\title{
Rapid post-earthquake damage assessment of ageing reinforced concrete bridge piers using time-frequency analysis
}

Xiao $\mathrm{Ge}^{1}$, Nicholas A. Alexander ${ }^{2}$, Mohammad M. Kashani ${ }^{3}$

\begin{abstract}
The role of signal-based nonlinear system identification methods for the rapid post-earthquake damage assessment of reinforced concrete (RC) bridge piers is explored. Experimental data from the shaking table tests of six RC columns with and without corrosion damage are used as benchmark data. The specimens are excited under three different ground motions with different time-series characteristics, structural detailing, and corrosion levels. The proposed system identification methods make use of accelerations alone (but not displacements as these are costly in-situ) to estimate the instantaneous frequency. The Wigner-Ville distribution and Hilbert transform are utilised due to their high resolution in both time and frequency domains.

A combination of modal filtering and thresholding, using instantaneous amplitudes, are employed to attenuate the unreliable spikes in the Hilbert transform's instantaneous frequency estimates. Their performance is benchmarked against a moving linear regression and standard white-noise tests. The comparison of the experimental results and time-frequency analysis indicates that the Wigner-Ville distribution and the Hilbert transform can produce reliable rapid damage detection when the response amplitude is large. The Wigner-Ville distribution has better robustness and higher resolution. The robustness of the more computationally efficient Hilbert transform can be significantly improved by the introduction of modal filtering and thresholding.
\end{abstract}

Keywords: post-earthquake damage assessment, nonlinear system identification, RC bridge piers, Wigner-Ville distribution, Hilbert transform

\footnotetext{
${ }^{1} \mathrm{PhD}$ Candidate, University of Bristol, University of Bristol, Dept. of Civil Engineering University of Bristol, Bristol, BS8 1TR, United Kingdom

2 Associate Professor in Structural Dynamics, University of Bristol, Dept. of Civil Engineering University of Bristol, Bristol, BS8 1TR, United Kingdom

3 Associate Professor, University of Southampton, Faculty of Engineering and Physical Sciences, Southampton, SO17 1BJ, United Kingdom (corresponding author, mehdi.kashani@soton.ac.uk)
} 


\section{Introduction}

The conventional seismic bridge design philosophy relies on plastic hinges occurring in bridge piers to dissipate energy (Caltrans, 2013; CEN.EN, 2010). Therefore, the seismic capacity and nonlinear behaviour of a bridge depend on its piers. The seismic performance of reinforced concrete (RC) piers is significantly affected by concrete cover spalling (Cusson \& Paultre, 1994; Dhakal \& Maekawa, 2002; Foster, 2001; Gaal, 2004; Lehman et al., 2004), core concrete crushing (Lehman et al., 2004; Sheikh \& Khoury, 1993; Shin \& Andrawes, 2011; Tobbi et al., 2014; Youssef \& Ghobarah, 1999), reinforcement yielding/fracture in tension(Kashani et al., 2018; Kim et al., 2005; Lehman et al., 2004; Thomson et al., 1998), rebar buckling in compression (Dhakal \& Maekawa, 2002; Kashani et al., 2018; Kim et al., 2005; Lehman et al., 2004), low-cycle fatigue degradation (El-Bahy et al., 1999; Kashani et al., 2018; Kim et al., 2005; Thomson et al., 1998), and corrosion damage (if the bridge is ageing) (Alipour et al., 2011; Choe et al., 2008; Dizaj et al., 2018, 2019; Ghosh \& Padgett, 2010; Kashani, Crewe, et al., 2017; Kashani, Maddocks, et al., 2019). This is especially the case for older bridges that do not have sufficient lateral tie/confinement reinforcement (Chang \& Mander, 1994). After earthquake events, bridges are crucial and strategic structures that enable a timely post-disaster rescue response. It is very important for decision-makers to know the reliability of the damaged bridges. In order to estimate the damage in a structure after the earthquake force and displacement responses are required. Inertial forces are relatively easily estimated by measuring accelerations (using an accelerometer) and the determination of a modal mass (which may require some in-situ ambient testing). Measuring the displacement time-series in-situ, during a

seismic event, is far more problematic. For example, a natural choice of Global Positioning System (GPS) generally does not have the necessary spatiotemporal resolution to be presently useful (Kijewski-Correa, 2005). The alternative technologies, such as local deformation (optical/strain) measurements, are far more expensive (Ahlborn et al., 2010). Hence, a rapiddamage assessment based on only response acceleration data is needed to help identify deficient bridges.

Conventionally, in earthquake engineering community, stiffness degradation under dynamic earthquake loading is used to quantify the damage in structures (El-Bahy et al., 1999; Kim et al., 2005). However, quantifying stiffness degradation of the damaged structures 
requires measuring force and displacement, which is not practical in real structures. An alternative to stiffness degradation is system frequency reduction. The advantage of frequency is that it can be estimated using response acceleration time-series alone. Hence, it can be used in the in-situ measurement of full-scale bridges.

Recently, several researchers introduced time-frequency representatives including the wavelet transform (WT) (Adeli \& Jiang, 2006; Cruz \& Salgado, 2009; Giurgiutiu \& Yu, 2003; Guo \& Kareem, 2016a; Khoa, 2013; Melhem \& Kim, 2003; Nagarajaiah \& Basu, 2009; Qiao et al., 2012; Spanos et al., 2007; Spanos \& Failla, 2005; Staszewski \& Robertson, 2007; Tang et al., 2010; Wong \& Chen, 2001), the Fourier transform (FT), the short-time Fourier transform (STFT) (El Shafie et al., 2012; Giurgiutiu \& Yu, 2003; Guo \& Kareem, 2016a; Melhem \& Kim, 2003; Nagarajaiah \& Basu, 2009), the Hilbert transform (HT) (Feldman, 2014; Kunwar et al., 2013; Loutridis, 2004; Pines \& Salvino, 2006; Roy et al., 2019; Salvino et al., 2003; Si et al., 2016) and the Wigner-Ville distribution (WVD) (Berinde et al., 2006; Bradford et al., 2006; G. Chen et al., 2013; Claasen \& Mecklenbräuker, 1980; Guo \& Kareem, 2016b; Martin \& Flandrin, 1985; Tang et al., 2010; Wu \& Chiang, 2009) as non-parametric system identification strategies (Salvino et al., 2003).

Khoa (2013) demonstrated the robustness of WT when the noise-to-signal ratio is under $15 \%$. Wong and Chen (2001) found the performance of WT is acceptable for structures with low non-linearity. Staszewski and Robertson (2007) suggested that the continuous WT has better performance in calculating structural instantaneous frequency than the discrete WT, although the continuous WT is computationally inefficient compared with the stationary and discrete WT. They also pointed out the resolution limitation of the wavelet transform, which significantly affects its adaptivity in system identification.

In terms of the usage of FT in system identification, El Shafie et al. (El Shafie et al., 2012) found that the STFT cannot remain robust when the moving window length is too small. Using the STFT always requires a trade-off between time and frequency resolution due to Heisenberg's uncertainty principle. Giurgiutiu and Yu (2003) pointed out that adjusting the window length in the STFT is problematic, while the WT can scale the window length by local frequency. Guo and Kareem (Guo \& Kareem, 2016a) modified the frequency response function to reduce the window effects of STFT and WT. Melhem and Kim (2003) use case studies to 
suggest that the STFT can work very well on stationary signals, while the WT is better for nonstationary signals. They also found the limitation of the STFT in damage detection of slab structures.

Staszewski and Robertson (2007) stated that the STFT has the same resolution problem as Li et al. (2017) conducted structural health monitoring of high-rise buildings based on the HT and found that the basic HT cannot accurately reflect the dynamic properties of the structure. In order to deal with highly non-linear and non-stationary signals, Huang et al. (1998) introduced the empirical mode decomposition (EMD) method. With this method (HilbertHuang transform (HHT)) the seed signal is decomposed into several intrinsic mode functions (IMF). The HT can be applied on IMFs separately which is eminently sensible as the Hilbert transform is a single valued function which is ill suited for a multi-frequency function case. EMD requires well separated modes with narrow banded frequencies. The limitations of EMD is discussed by some researchers (Y. Chen \& Feng, 2003; Dätig \& Schlurmann, 2004).

Bradford et al. (2006) validated the implement of WVD in detecting the frequency evolution of multi-floor buildings during earthquakes. The apparent resolution of WVD is significantly improved compared with other time-frequency analysis methods, because of the introduction of the instantaneous auto-correlation function of time and frequency (Claasen \& Mecklenbräuker, 1980; Staszewski \& Robertson, 2007). However, the instantaneous autocorrelation function is a combination of the signal in past and future. The overlapped signal causes interferences, which generates unexpected spurious small oscillations (Staszewski \& Robertson, 2007) because there is, after all, no way of circumventing completely Heisenberg's uncertainty principle. To avoid this cross-term problem of WVD, Chen et al. (2013) suggested using the Chirplet transform to convert the signal into signals with mono-frequency.

The aim of this paper is to investigate if either the WVD or some modified version of HT can capture the time-frequency evolution (and hence damage) of a degrading RC column during a moderate and large seismic event. The proposed methods are aimed to be used in rapid assessment of the damage severity of RC bridge piers during earthquake events through timefrequency analysis methods. To this end, a case study of a series of shaking table tests on six large-scale RC columns is introduced. This group of experimental tests vary in terms of input ground motion characteristics, structural detailing and corrosion levels. Considering the 
advantages and drawbacks of time-frequency representatives reviewed above, the HT (using output acceleration) and the WVD (using input \& output accelerations) algorithms are selected as signal processing methods to evaluate instantaneous frequency variation of the $\mathrm{RC}$ columns under seismic excitations with different intensities. A moving linear regression (MLR) (using both experimental force and displacement responses) and standard linear system identification white-noise tests are used to benchmark the nonlinear system identification methods.

The proposed methods are supposed to be used in rapid assessment of bridges ageing bridges after seismic events. The WVD and the modified HT only require the data (output or input/output) measured by accelerometers attached on bridge piers, which can avoid extensive instrumentation used in conventional structural health monitoring approaches. The signal processing (the WVD or the HT) of the acceleration data takes only a few minutes without needing extensive data or any specific software, which can help decision makers organise rescue plan after major earthquakes in a short time.

\section{Shaking table experimental testing and results}

In order to investigate the seismic behaviour of uncorroded and corroded RC bridge piers in terms of the effects of ground motion characteristics, structural detailing and corrosion levels, a series of shaking table tests are conducted on six large-scale RC columns. The experimental campaign is included four uncorroded and two corroded columns (Ge et al., 2019; Kashani, Ge, et al., 2019). The columns with cross-sections of $250 \mathrm{~mm} \times 250 \mathrm{~mm}$ are cast in a $1500 \mathrm{~mm} \times$ $700 \mathrm{~mm} \times 300 \mathrm{~mm}$ foundation. The specimens are vertically reinforced with eight $16 \mathrm{~mm}$ diameter reinforcing steel bars. Three specimens are well confined with ties at $80 \mathrm{~mm}$ spacings. The other three specimens are lightly confined with ties at $200 \mathrm{~mm}$ spacings. The configuration of the specimens is shown in Figure 1.

Two of the lightly confined columns are corroded using accelerated corrosion procedure (Kashani, Crewe, et al., 2017). The total reinforcement mass loss ratio of the two specimens are $51 \%$ and $65 \%$, respectively. The ground motion records of Northridge [near-field without pulse (NFWP)], Imperial Valley [near-field pulse-like (NFPL)], and Manjil [far-field (FF)] earthquakes suggested in FEMA P695 (FEMA-P695, 2009) and provided by NGA-West2 database (Ancheta et al., 2013) are selected, to evaluate the effects ground motions 
characteristics on nonlinear structural response. The shaking table test setup is shown in Figure 2. The identifications of six columns are summarised in Table 1.

Using a MATLAB (The MathWorks Inc., 2019) toolbox developed by Alexander et al. (2014) that employs Volterra series the seed ground motion records are matched to the mean response spectrum of all the FF ground motions suggested in FEMA P695 (FEMA-P695, 2009) [details are available in Kashani et al. (Kashani, Málaga-Chuquitaype, et al., 2017)]. The three well-confined specimens are tested under the three matched ground motions (shown in Figure $3)$.

Three lightly confined columns are tested under the matched FF ground motion. Amplitude scale factors of $25 \%$ (slight) followed by $300 \%$ (extensive) for ground motions are used to investigate the cascade effect on the seismic performance of RC columns. Before the first round and after each round of testing, a low-amplitude $(0.0043 \mathrm{~g})$ linear system identification whitenoise test is carried out to characterise the dynamic properties of the test specimens. During the tests, the in-plane acceleration and displacement responses of the column top are recorded through accelerometers and cable extension position transducers (i.e. Celescos). In this section, only a summary of the experimental results is provided. The detailed discussion of experimental results and structural damage are beyond the scope of this paper and are reported in different publications (Ge et al., 2019; Kashani, Ge, et al., 2019). 


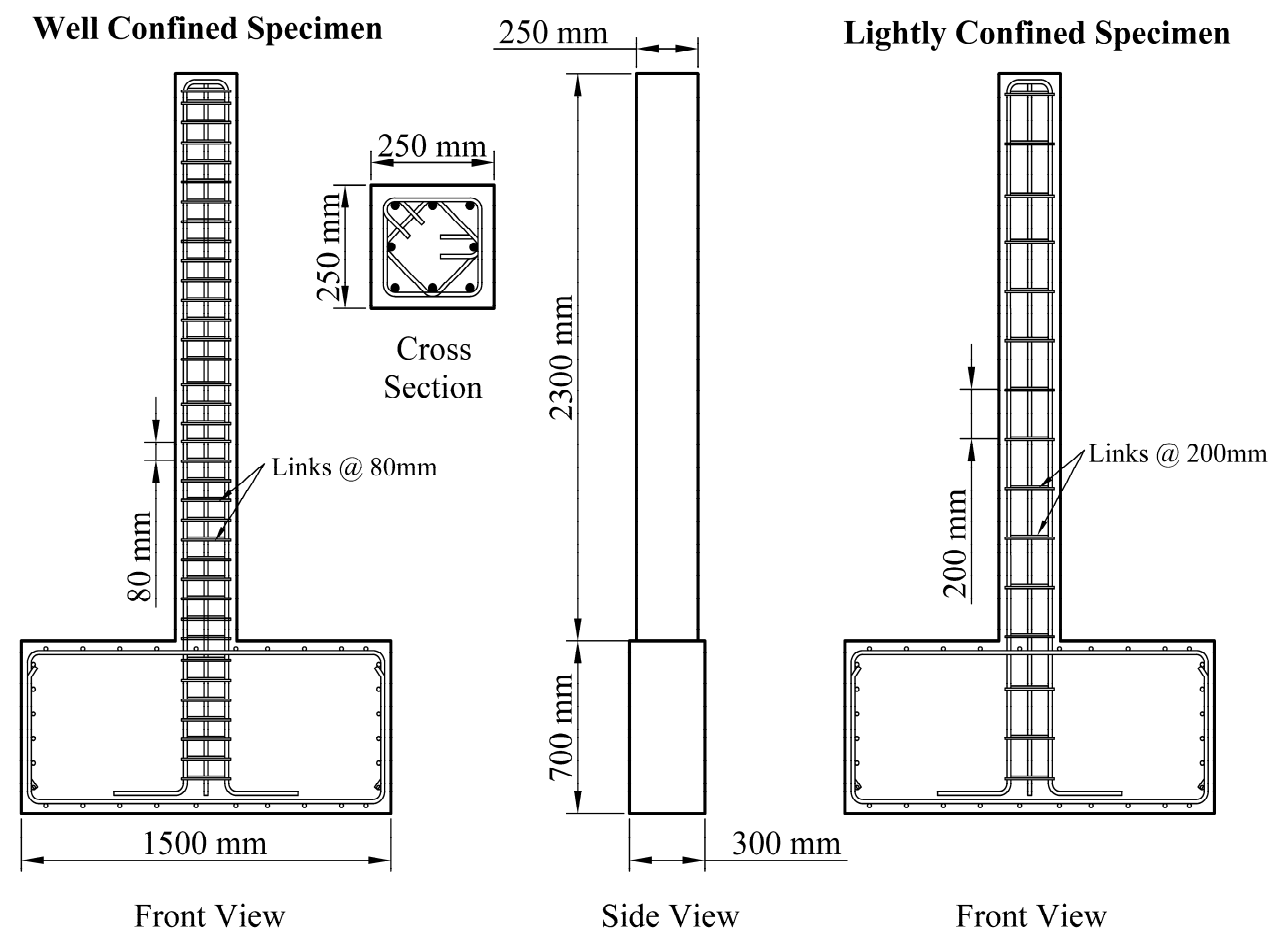

Figure 1. The structural configuration of the specimens.

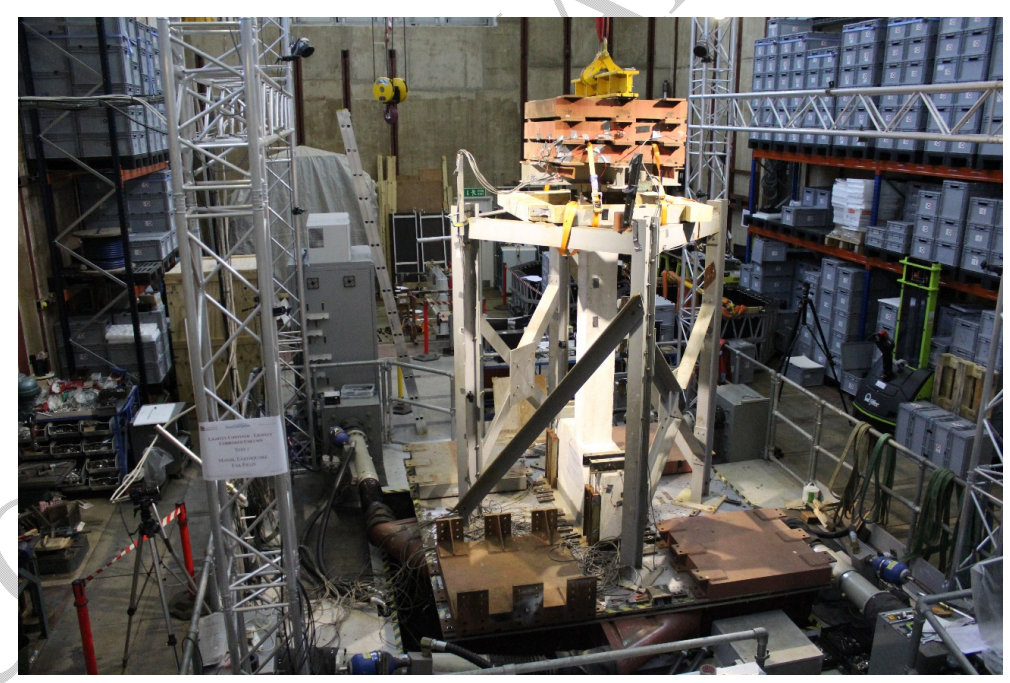

Figure 2. The setup of the shaking table test. 


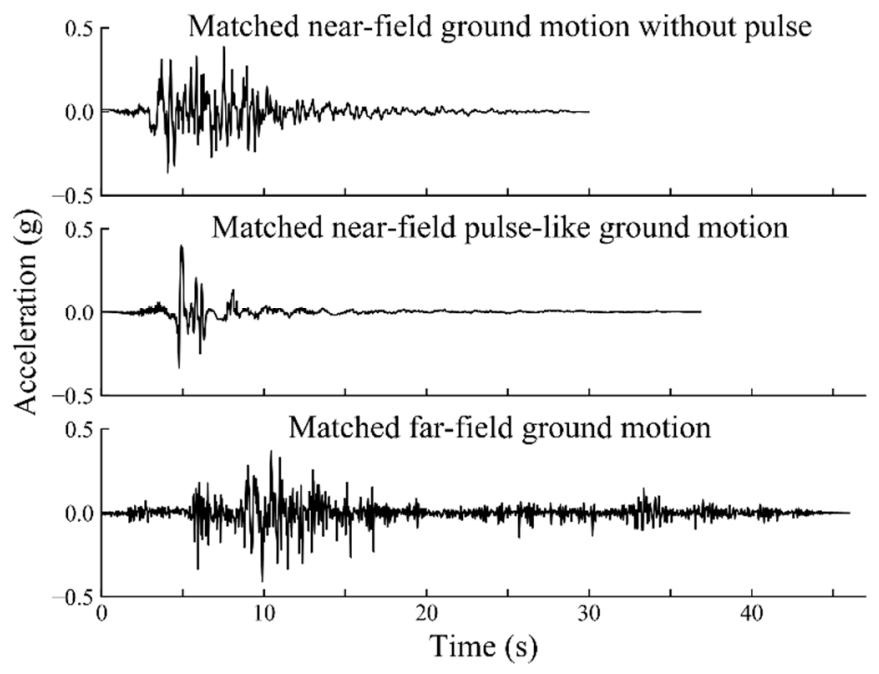

Figure 3 . The spectrally matched input ground motion records.

Table 1. Identifications of all specimens.

\begin{tabular}{cccc}
\hline Specimen & Ground Motion & Confinement & Corrosion level \\
\hline NFWP & Near-field without pulse & Well confined & $0 \%$ \\
NFPL & Near-field pulse-like & Well confined & $0 \%$ \\
FF-WC & Far-field & Well confined & $0 \%$ \\
FF-LC-UnCorr & Far-field & Lightly confined & $0 \%$ \\
FF-LC-Corr1 & Far-field & Lightly confined & $51 \%$ \\
FF-LC-Corr2 & Far-field & Lightly confined & $65 \%$ \\
\hline
\end{tabular}

The inertial force is obtained by acceleration time-history with multiplying the column's first modal mass ( 3 tonnes). The hysteretic loops of all specimens in slight $(25 \%)$ and extensive $(300 \%)$ damage levels tests are plotted in Fig. 4 and5. The uncorroded specimens exhibit pseudo-linear response in slight $(25 \%)$ damage level tests, while the corroded ones show significant degradation. In extensive (300\%) damage level tests, concrete spalling and steel yielding were observed on the uncorroded specimens. The uncorroded specimens exhibit significant hysteretic response in this round of tests.

The FF-LC-Corr1 specimen failed after 10s in the extensive (300\%) damage level test. The FF-LC-Corr2 lost most of its seismic capacity in this round. The "negative stiffness" shown 
in hysteretic loops indicates the rocking response of this specimen. The experiment illustrates that (i) the ground-motion type and duration affect the peak displacement response owing to the excitation amplitude; (ii) the stiffness degradation of the $\mathrm{RC}$ column is mainly caused by concrete cover spalling and core crushing in well confined columns, and this factor is aggravated by inelastic buckling of the vertical reinforcement in lightly confined columns; (iii) compared with uncorroded RC columns, the corroded ones exhibit larger displacement response, smaller ultimate strength and less energy dissipation capacity due to corrosioninduced concrete cracking and steel bar fracture. The detailed discussion of the experimental findings can be found in the authors' previous works (Ge et al., 2019; Kashani, Ge, et al., 2019).
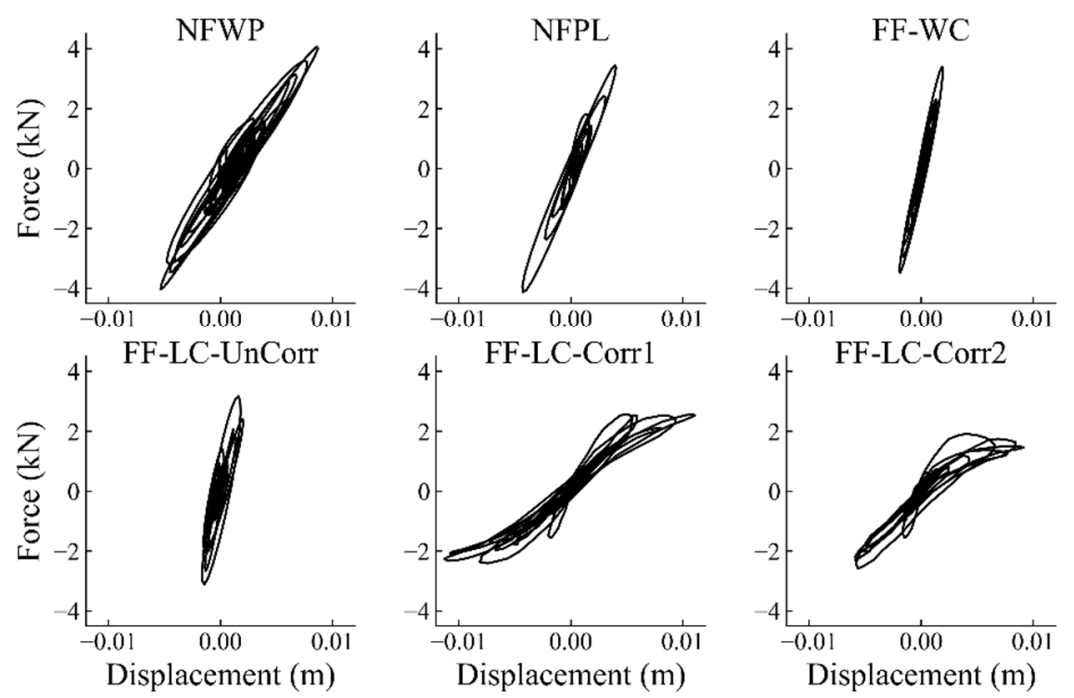

Figure 4. The hysteretic loops of all specimens in slight (25\%) damage level tests. 

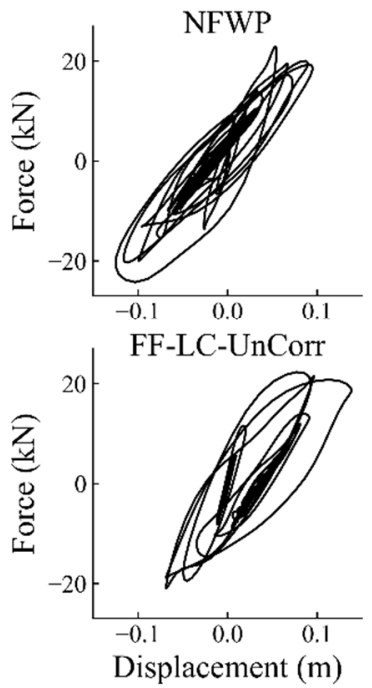

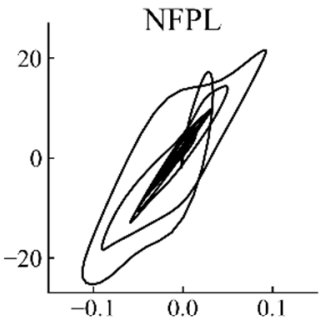

FF-LC-Corr1

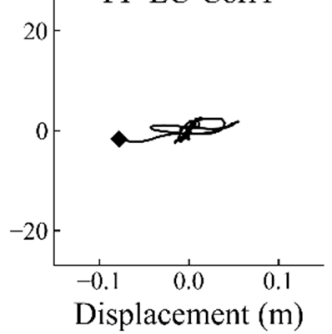

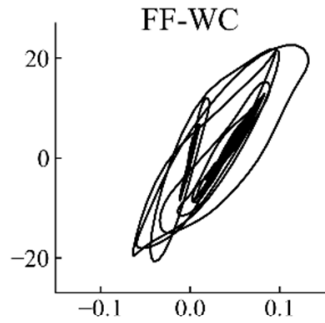

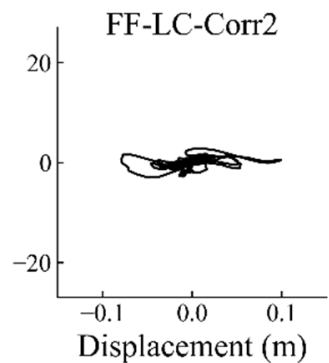

Figure 5. The hysteretic loops of all specimens in extensive (300\%) damage level tests.

\section{White-noise linear system identification before and after seismic tests}

The transfer function estimate (TFE) based on the low-amplitude white noise test is commonly used to conduct non-destructive linear system identification in laboratory conditions. In this work, the white-noise (WN) tests are carried out on the six specimens before and after the main shaking table tests. It can indicate the structural property variation caused by either static corrosion damage or seismic impact in the test flow. With the white-noise signal and the corresponding column acceleration response trace, the cross-power spectral density (between input and output) can be used to estimate the system linear transfer function using a MATLAB toolbox (The MathWorks Inc., 2019), developed by Vold et al. (1984). The transfer functions illustrate the first two modes of structural response. In this work, only the natural frequency variation of the first mode response (i.e. the fundamental frequency) is focused. The natural frequencies are listed in Table 2. The FF-LC-Corr1 column failed during extensive damage level $(300 \%)$ test. Therefore, the natural frequency is regarded as $0 \mathrm{~Hz}$. Note that these estimated structural mode 1 frequencies are (i) only for very small amplitude oscillations that do not allow crack opening to any significant degree and hence tend to be overestimates, additionally (ii) they do not give information about the variation of structural frequencies during a strong seismic event. 
Table 2. The white-noise estimated fundamental frequencies of all specimens.

\begin{tabular}{ccccccc}
\hline & NFWP & NFPL & FF-WC & FF-LC-UnCorr & FF-LC-Corr1 & FF-LC-Corr2 \\
\hline Pristine & 2.86 & 3.35 & 3.57 & 3.66 & 3.21 & 3.21 \\
After 25\% & 2.62 & 3.13 & 3.51 & 3.41 & 2.71 & 2.71 \\
After 300\% & 1.67 & 1.64 & 1.66 & 1.53 & 0 & 2.20 \\
\hline
\end{tabular}

Unit: $\mathrm{Hz}$

\section{Real-Time Nonlinear System Identification}

\subsection{Moving linear regression (MLR) of force-displacement hysteretic response} (Benchmark)

The use of both acceleration and displacement responses and the $1^{\text {st }}$ modal mass enables force-deflection hysteretic loops to be plotted as shown in Fig. 4 and 5. Using a moving linear regression (MLR) type approach the variation of the structure's averaged real-time stiffness variation can be estimated. A smoothing low-pass filter with a cut-off frequency of $5 \mathrm{~Hz}$ is also employed to isolate the first mode from other higher mode responses. Given an appropriate modal mass $M$, the instantaneous stiffness $K_{i}$ can be converted to instantaneous frequency $f_{i}$ [as shown in Equation (1) and Equation (2)].

$$
\begin{gathered}
{\left[\begin{array}{c}
F_{i-N} \\
\vdots \\
F_{i+N-1}
\end{array}\right]=\left[\begin{array}{cc}
1 & X_{i-N} \\
\vdots & \vdots \\
1 & X_{i+N-1}
\end{array}\right]\left[\begin{array}{c}
c_{i} \\
K_{i}
\end{array}\right]} \\
f_{i}=\frac{1}{2 \pi} \sqrt{\frac{K_{i}}{M}}
\end{gathered}
$$

where $F_{i}$ and $X_{i}$ are inertial force and relative displacement at each time point. $f_{i}$ and $K_{i}$ are instantaneous frequency and instantaneous stiffness of the specimen. $M$ denotes the modal mass ( 3 tonnes).

The underline trend becomes smoother as the window length $2 N$ in Equation 1 increases. However, this increased noise attenuation comes at a cost of a loss of the resolution in time. A reasonable compromise is obtained for these specimens with a window length between $3 \mathrm{~s}$ and 9s. Figures 6 and 7 show the estimated time-varying frequency response for all the specimens in slight (25\%) and extensive (300\%) damage level tests. Consider Figure 6 (a) which shows the estimated predominant time-frequency using Equations 1 and 2 for pier NFWP at the 25\% 
amplitude level of shaking. At time location $\mathrm{t}=4.5 \mathrm{~s}, 8.2 \mathrm{~s}, 10.1 \mathrm{~s}$, and $13.8 \mathrm{~s}$ we plot, qualitatively, the time-windowed force-displacement hysteretic loops as four subplots. The Celesco instruments for measuring displacement are noisy when the displacement levels below $0.03 \mathrm{~mm}$. Thus, below this displacement level (for very small oscillations) the recovered time-frequency estimates (from this method) are unreliable, and hence, we threshold the data.

In the main time-frequency graphs, the bold black lines indicate reliable estimates of frequency while the faint grey lines indicate the erroneous frequency estimates due to very low displacements of the pier. It is clear that the uncorroded columns at $25 \%$ level of excitation [Figures 6(a-d)] had oscillations that were small enough to produce significant regions of unreconstructable time-frequency using MLR. While the corroded columns Figures 6(e) and (f) (that were damaged) and all columns at the $300 \%$ shaking amplitude levels demonstrated a reasonable time-frequency reconstruction using MLR. Note that column FF-LC-Corr1 collapsed at $300 \%$ excitation so no time-frequency reconstruction is attempted.

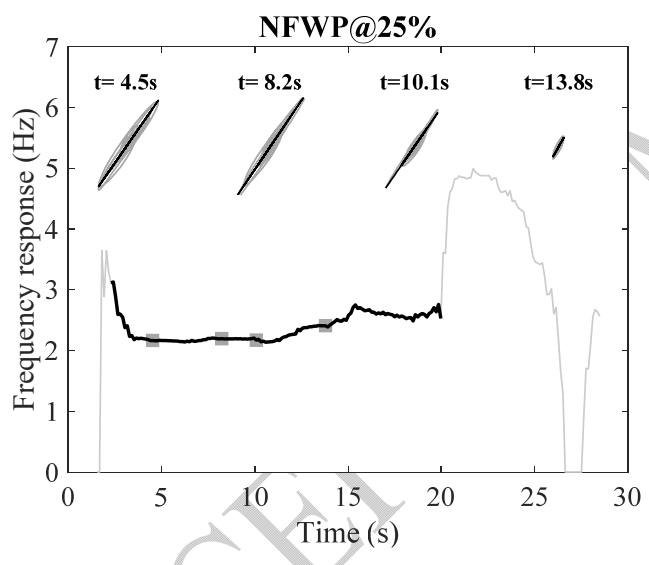

(a)

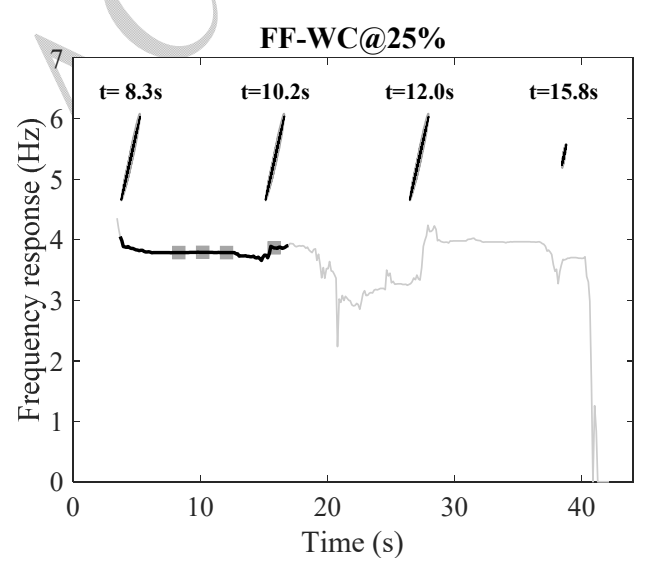

(c)

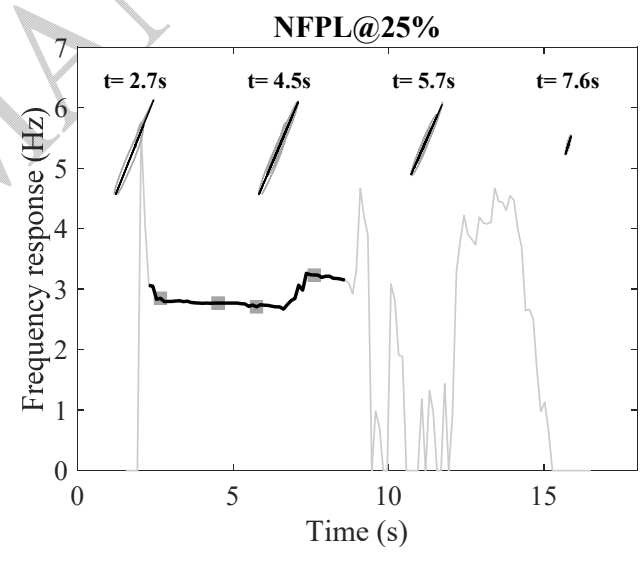

(b)

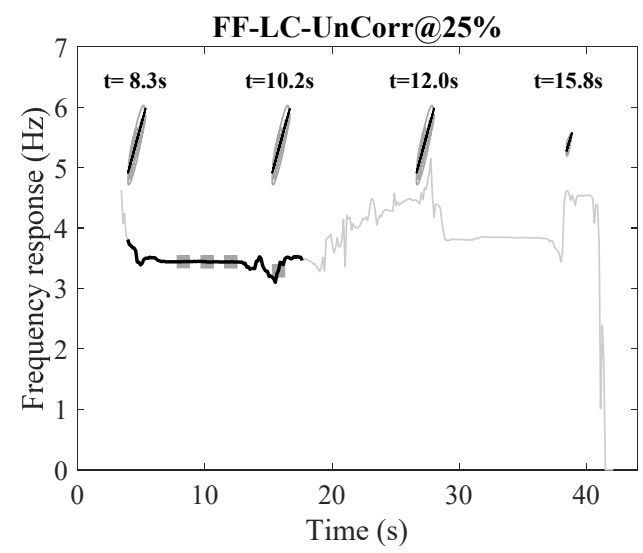

(d) 


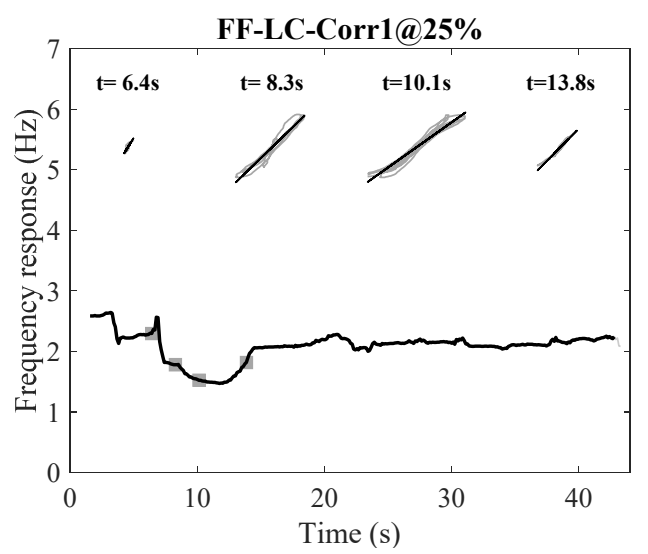

(e)

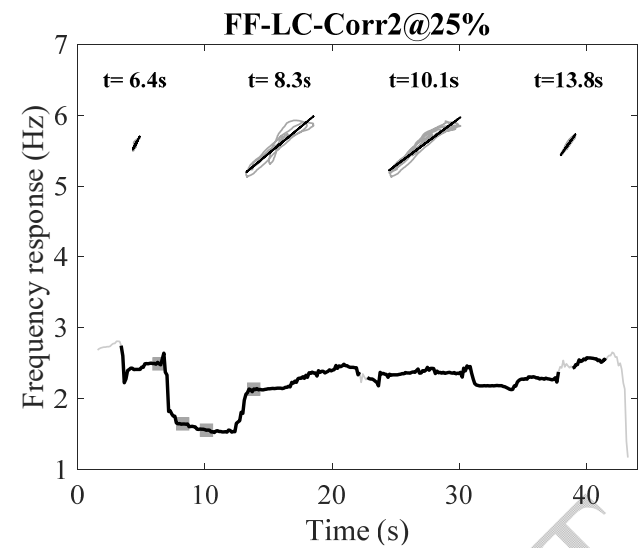

(f)

Figure 6. Frequency responses of all specimens at slight (25\%) damage level tests obtained by MLR.

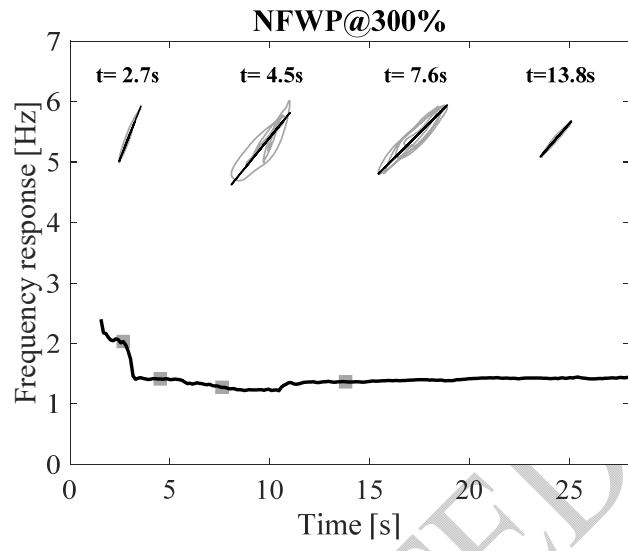

(a)

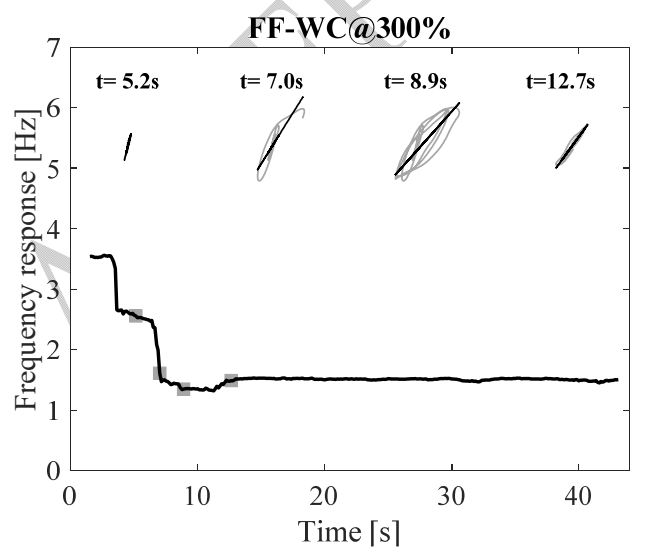

(c)

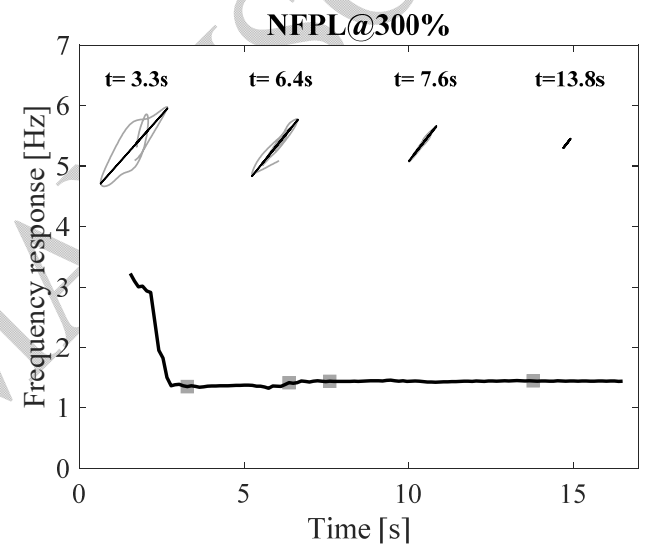

(b)

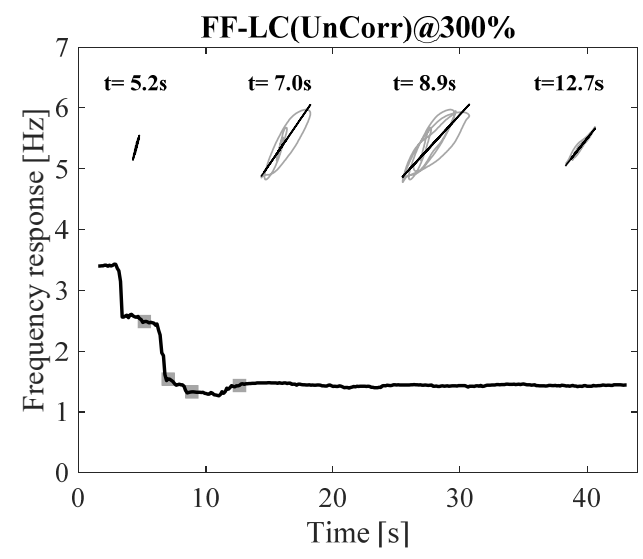

(d) 


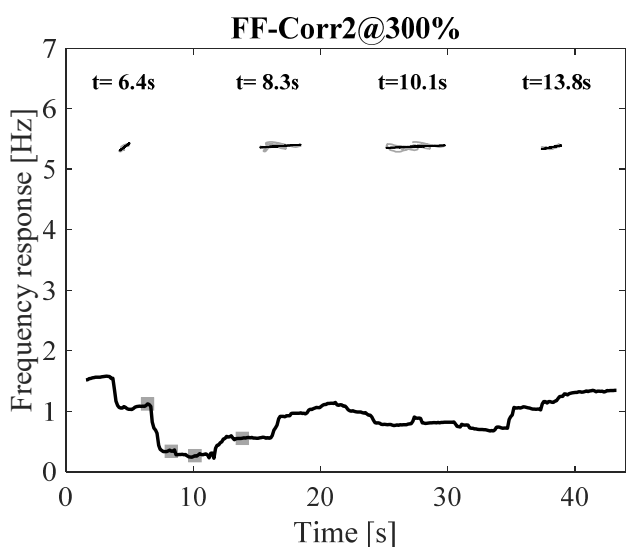

(e)

Figure 7. Frequency responses of all specimens at extensive (300\%) damage level tests obtained by

MLR.

\subsection{Time-frequency estimates using a smoothed and thresholded Hilbert transform} algorithm (using only acceleration measurements)

In this section, the change in frequency is estimated with acceleration responses alone, the smoothed Hilbert transform algorithm is employed. Given a real time-series signal $x(t)$, a complex analytical signal $s(t)=x(t)+i y(t)$ can be constructed where $y(t)$ is obtained from the Hilbert transform (HT) of $x(t)$. With this analytical signal, the envelope of $x(t)$ and the instantaneous phase and frequency of $x(t)$ can be obtained (Feldman, 2014) by the following equations

$$
\begin{gathered}
A(t)=|s(t)|=\sqrt{x(t)^{2}+y(t)^{2}} \\
f(t)=\frac{\mathrm{d}}{\mathrm{d} t}\left(\arctan \left(\frac{y(t)}{x(t)}\right)\right)=\frac{1}{2 \pi} \frac{x(t) \dot{y}(t)-y(t) \dot{x}(t)}{A(t)^{2}}
\end{gathered}
$$

where, the envelope $A(t)$ (instantaneous amplitude) of signal $x(t)$ is defined in Equation 3 and the instantaneous frequency $f(t)$ of signal $x(t)$ is given by Equation 4 . The problems with Equation 4 as self-evident (i) it is a single-valued function hence can only produce one "averaged" frequency at each unique time location and (ii) when the amplitude $A(t)$ drops to zero the frequency estimate $f(t)$ is likely to suffer from spikes $( \pm \infty)$. The solution to problem (i) is to band-limit filter signal $x(t)$ to a specific structural mode. In this system, the authors focus on mode 1, and high-cut zero-phase filter at $5 \mathrm{~Hz}$ using a low order Butterworth 
filter. To eliminate the unexpected spikes (problem (ii)), Matheney and Nowack (1995) proposed that adding a damping factor $\varepsilon$ to the dominator of the derivative of the instantaneous phase. In this work, the authors found this method attenuates the signal spikes. However, the trend-line in instantaneous frequency is reduced after adding the damping factor $\varepsilon$. Choosing a 'correct' value of $\varepsilon$ was problematic. Therefore, the authors choose the more reliable approach of introducing a high-pass threshold of instantaneous frequency based on the signal's amplitude $A(t)$, as follows

$$
f(t)=\left\{\begin{array}{rc}
\alpha t+\beta, & A(t)<0.1 \max |A(t)| \\
f(t), & \text { Otherwise }
\end{array}\right.
$$

If the signal amplitude falls below $10 \%$ of its maximum then it is assumed the unwanted spikes will dominate the reconstructed instantaneous frequency estimates. Hence, a linear trend line is employed. The linear trend-line coefficients $\alpha$ and $\beta$ are determined so as to match the frequency estimates at the threshold amplitude either side of this region. This method relies, to some extent, on the choice of threshold level (here $10 \%$ ). A lower threshold results in a larger number of spikes while a higher threshold results in smaller regions in time where the instantaneous frequency is obtainable. Therefore, we further explore the use of a smoothing filter on $f(t)$ that removes remaining fluctuations above $0.5 \mathrm{~Hz}$. The fluctuations are most likely a mathematical artefact of Equations. 4 and 5, not reflecting any physical variation of the specimen. Hence, a smoothing filter is recommended here.

It should be noted that some researchers (Feldman, 2014; Huang et al., 1998) reported that the HT has an end effect problem which is due to the use of the Fourier transform in determining $y(t)$. The instantaneous frequency at the beginning and the end is not credible due to the signal step discontinuity between the beginning and end. This is somewhat similar to the "Gibbs effect". To eliminate these end effects, the first and the last estimated frequency values are set as the first and the last frequency estimated at amplitude levels equal to the threshold.

The frequency responses of all the columns in slight (25\%) and extensive (300\%) damage level tests obtained by this proposed extended HT are plotted in Figures 8 and 9. 

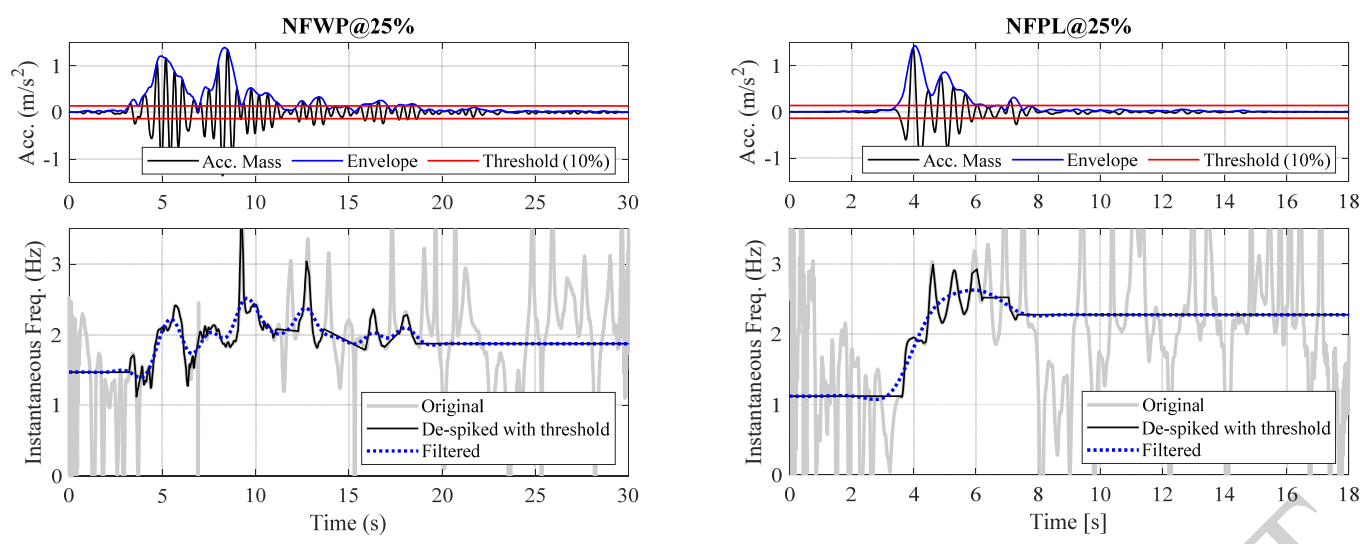

(a)

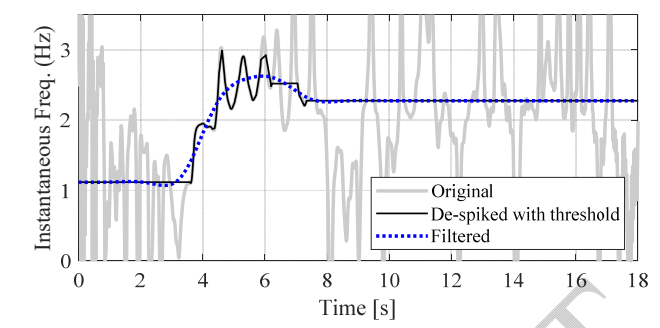

(b)
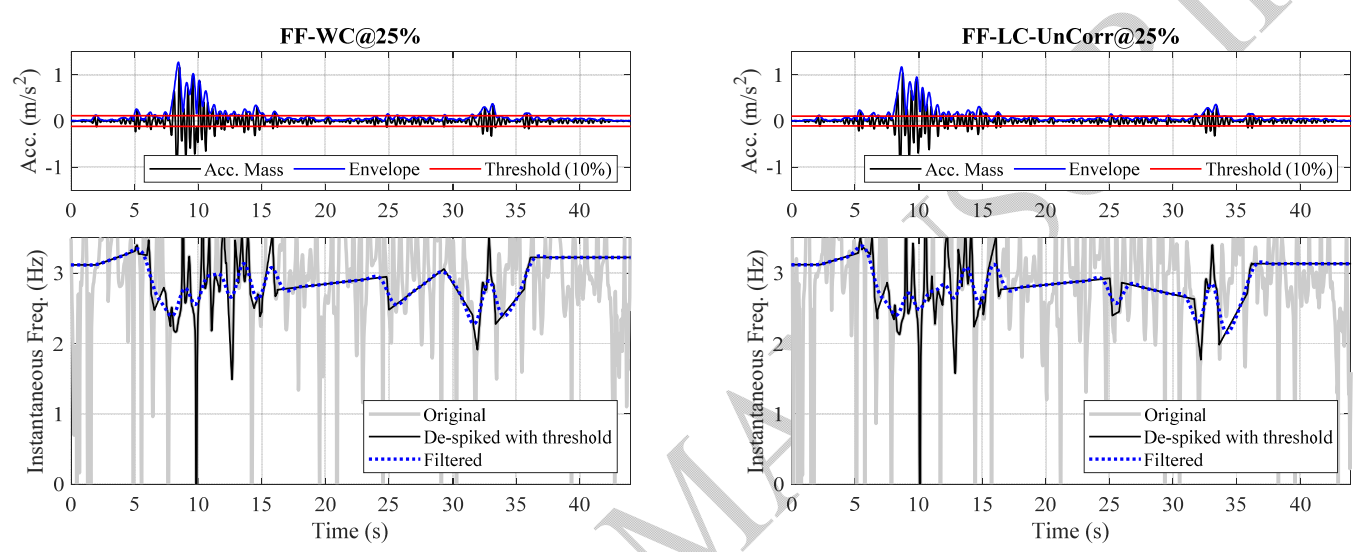

(c)

(d)

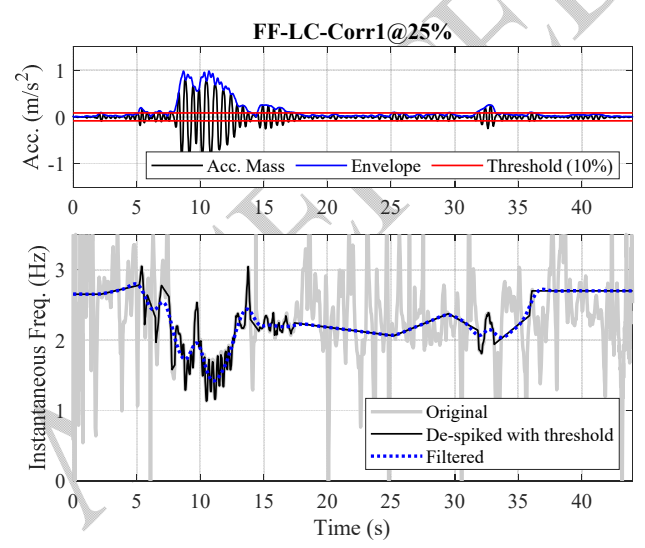

(e)

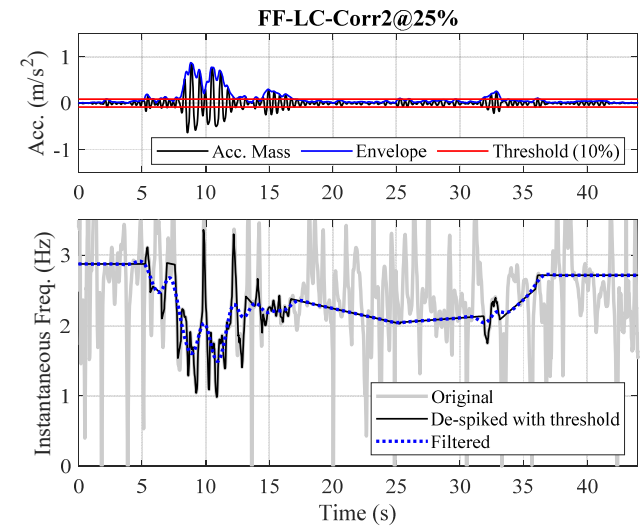

(f)

Figure 8 . Frequency responses of all specimens at slight (25\%) damage level tests obtained by the smoothed Hilbert transform. 

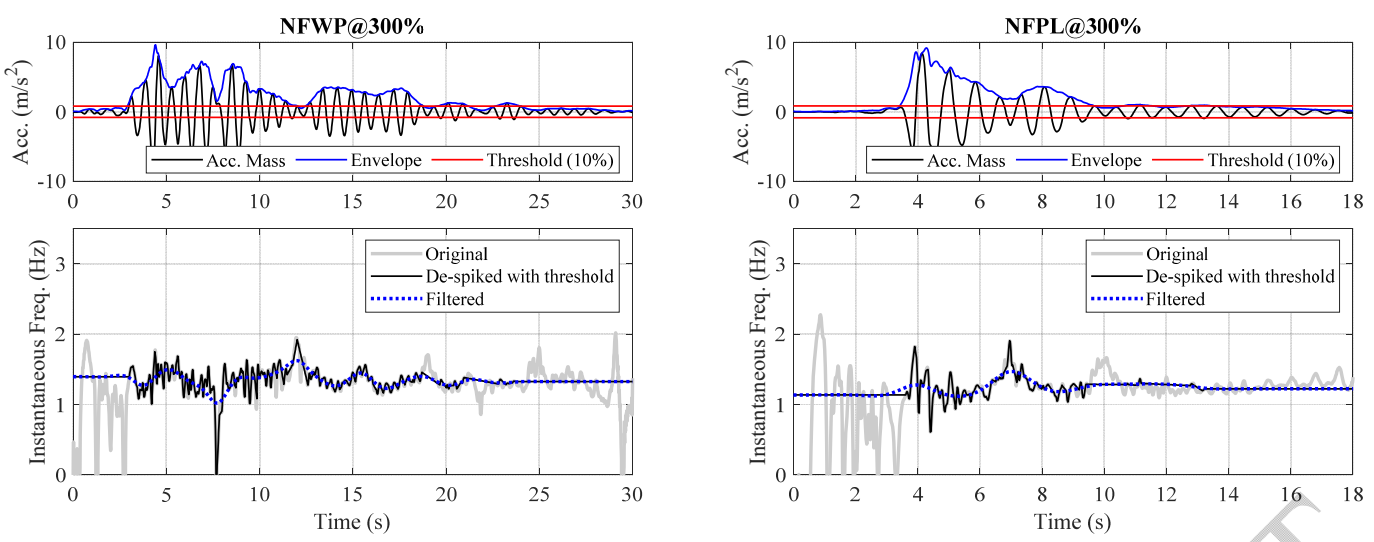

(a)

(b)
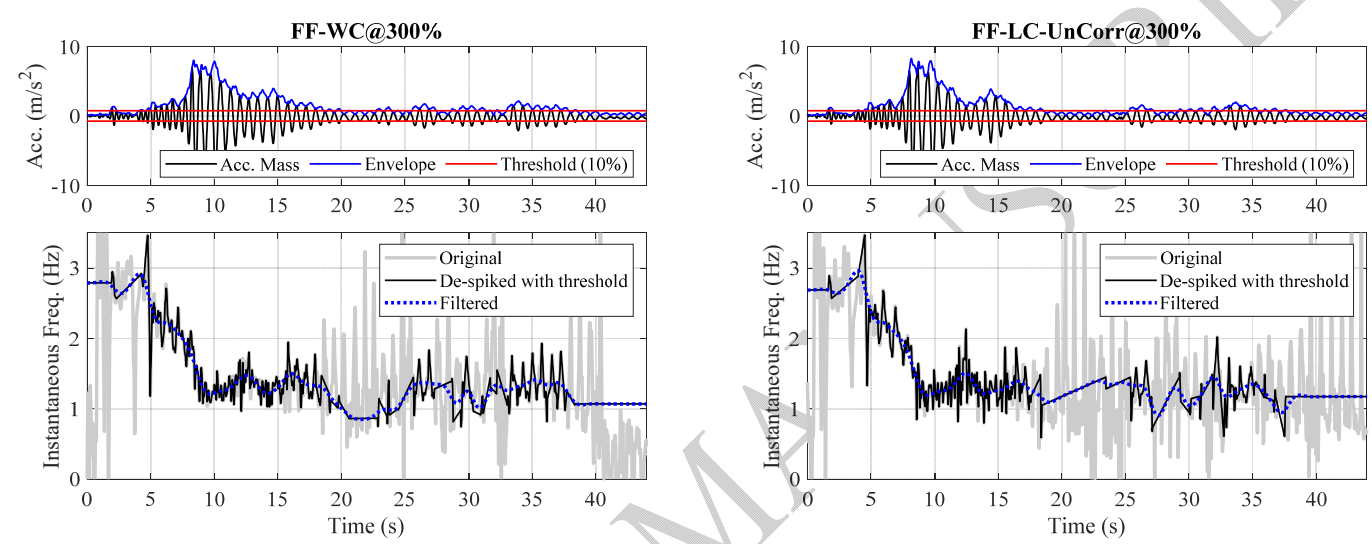

(c)

(d)

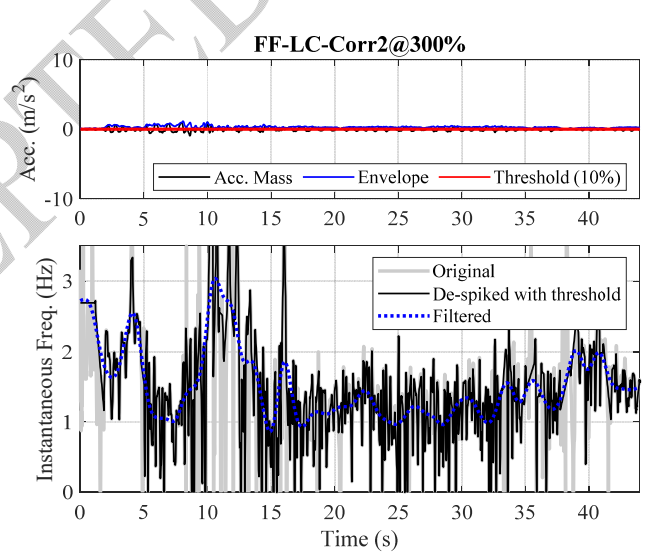

(e)

Figure 9. Frequency responses of all specimens at extensive (300\%) damage level tests obtained by the smoothed Hilbert transform. 
4.3 Time-frequency estimates using the Wigner-Ville distribution algorithm (only acceleration measurements)

The Wigner-Ville distribution (WVD) is another time-frequency analysis method. The WVD is widely used in system identification and can provide a high-resolution solution in both time and frequency domain (Staszewski \& Robertson, 2007). The algorithm was originally developed by Wigner (1932) and later modified by Ville (1948). It is defined as,

$$
W_{x}(t, f)=\int_{-\infty}^{\infty} x(t+\tau / 2) x^{*}(t-\tau / 2) e^{-j 2 \pi f \tau} \mathrm{d} \tau
$$

where $\tau$ is the time lag. When $\tau= \pm \infty$, determining $x(t+\tau / 2) x^{*}(t-\tau / 2)$ is problematic. Therefore, the WVD is redefined as a window version, which is known as pseudo Wigner-Ville distribution (PWVD).

$$
P W_{x}(t, f)=\int_{-\infty}^{\infty} h(\tau) x(t+\tau / 2) x^{*}(t-\tau / 2) e^{-j 2 \pi f \tau} \mathrm{d} \tau
$$

where $h(t)$ is a regular window with a length of $\tau$. It smooths the distribution in the frequency domain. Equation (5) can be equivalently expressed as:

$$
P W_{x}(t, f)=\int_{-\infty}^{\infty} H(f-\xi) W_{x}(t, \xi) \mathrm{d} \xi
$$

where $H(f)$ is the Fourier transform of $h(t)$. Since $h(t)$ is an instantaneous window in the frequency domain, to smooth distribution in the time domain, a separable smoothing function [Equation (9)] is added to PWVD. The resolution adjustable WVD is obtained. It is known as smoothed pseudo Wigner-Ville distribution (SPWVD). The detailed explanation of the SPWVD algorithm can be found in the toolbox tutorial of Auger et al. (1996).

$$
\begin{gathered}
\Pi(t, f)=g(t) H(-f) \\
S P W_{x}(t, f)=\int_{-\infty}^{\infty} h(\tau) \int_{-\infty}^{\infty} g(s-t) x(s+\tau / 2) x^{*}(s-\tau / 2) \mathrm{d} s e^{-j 2 \pi f \tau} \mathrm{d} \tau
\end{gathered}
$$


The SPWVDs of input/output acceleration time-histories of the six columns at slight (25\%) and extensive (300\%) damage excitation experiment are generated (plotted in Figures 11 and 12). The colour contour plots show the power distribution with respect to time and frequency of the response acceleration in log scale. A typical jet colour scheme is employed, low power is blue, high power is red. The first thing to note here is that, unlike the Hilbert transform, the Wigner-Ville distribution can identify multiple frequency components for any time $t$.

To compare the results with the MLR and the Hilbert transform approaches, only the frequency component with the maximum power at each time point should be selected. However, the power density from a pair of ridges of peaks (in the Wigner-Ville distribution) may have approximately equivalent values. Thus, sudden changes in instantaneous frequency may only signify a particular ridge-line of peaks is now maximum not a genuine physical property change of the specimen. The spectra of the NFPL specimen in $25 \%$ test at two close time points are plotted as an example (Figure 10). The distributions of the two spectra are very similar. However, the two power density maxima indicate that the instantaneous frequency suddenly jumps from the high-frequency ridge-line to a lower frequency ridge-line. This is an artefact of the method rather than a sudden system change in the specimen. So care is required if singlevalued maxima are used to interpret these plots. To avoid this sudden shift of the instantaneous frequency, the predominant frequency $f_{p}$ is determined by the centroid of the spectrum as Equation 11. Further ridge analysis for system with high precision requirement can be conducted through the method proposed by Iatsenko et al. (2016).

$$
f_{p}(t)=\frac{\int_{0}^{5} f . S P W_{x}(t, f) \mathrm{d} f}{\int_{0}^{5} S P W_{x}(t, f) \mathrm{d} f}
$$

It is worth noting that the calculation of the centroid is focused in the interval of $0-5 \mathrm{~Hz}$ of the spectra. This is because only mode 1 is focused in this work and to be consistent with the other methods employed. If the centroid is calculated using the whole Nyquist frequency range, the corresponding predominant frequency of the spectral centroid will be overestimated. As shown in Fig. 10, the change of predominant frequency in a short time indicated by centroids 
(blue and red squares) is much more reasonable. Therefore, the predominant frequency of each time point is more credible than the frequency corresponding to the power density maxima. This approach works reasonably well at high power levels, but it is sensitive to aleatory errors at low power levels.
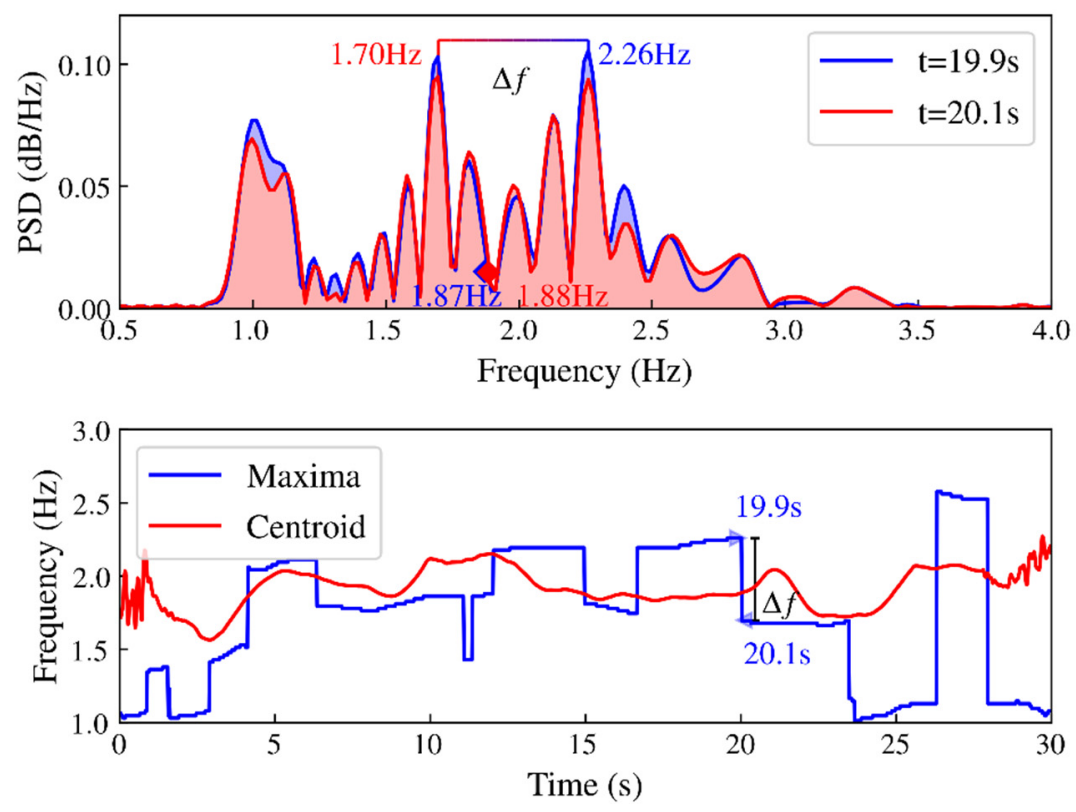

Figure 10 . The power density spectra of NFWP $(25 \%)$ at $t=19.9 \mathrm{~s}$ and $\mathrm{t}=20.1 \mathrm{~s}$.

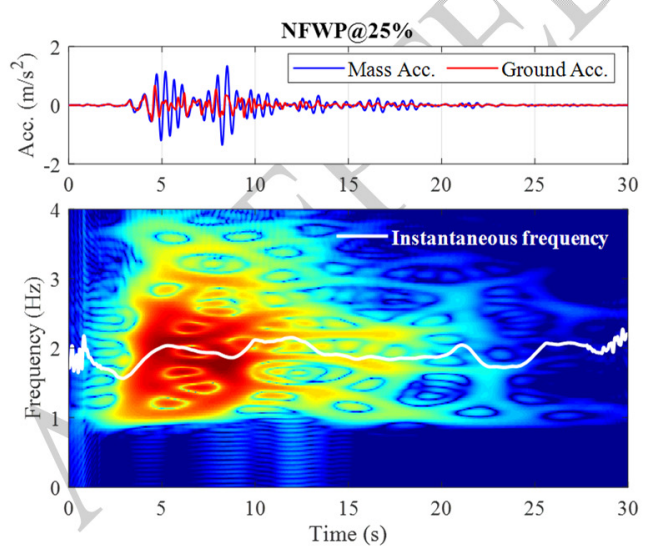

(a)
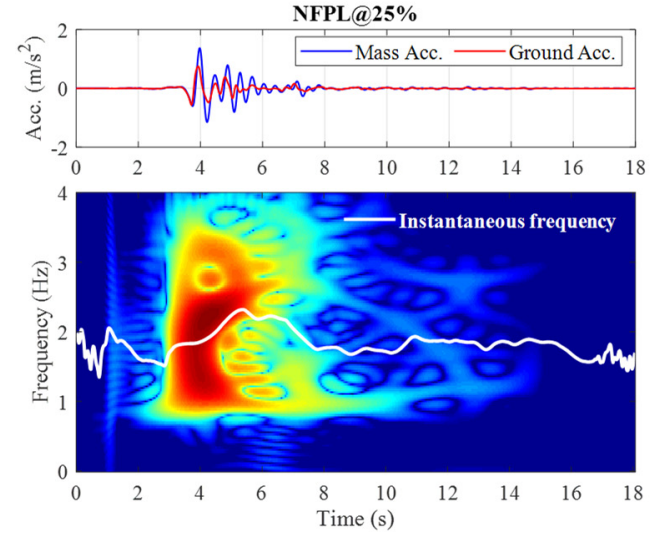

(b) 


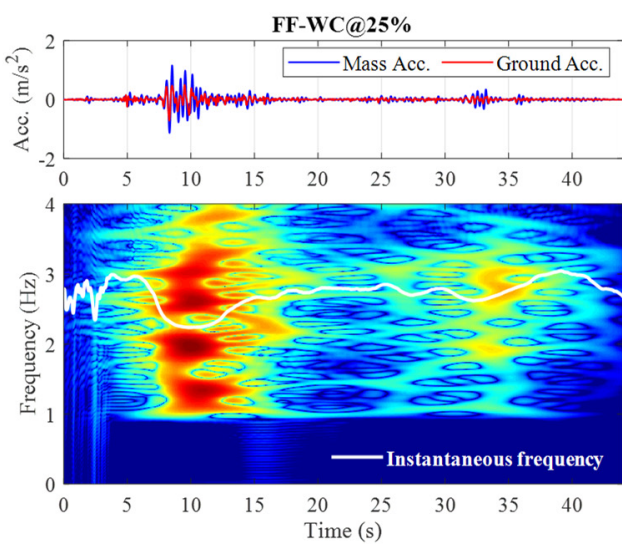

(c)
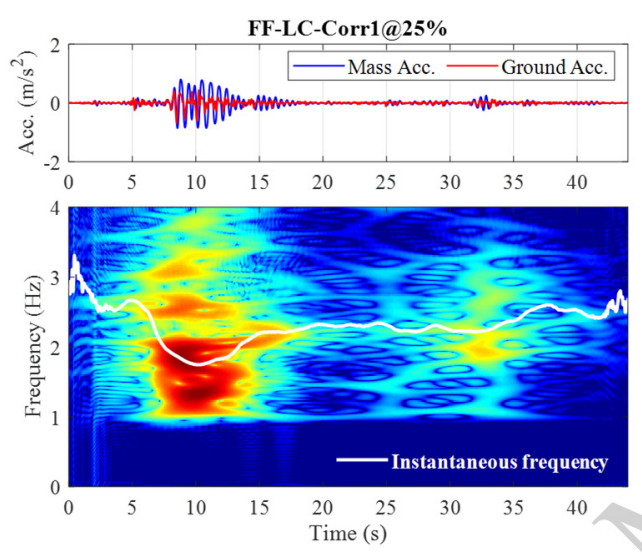

(e)
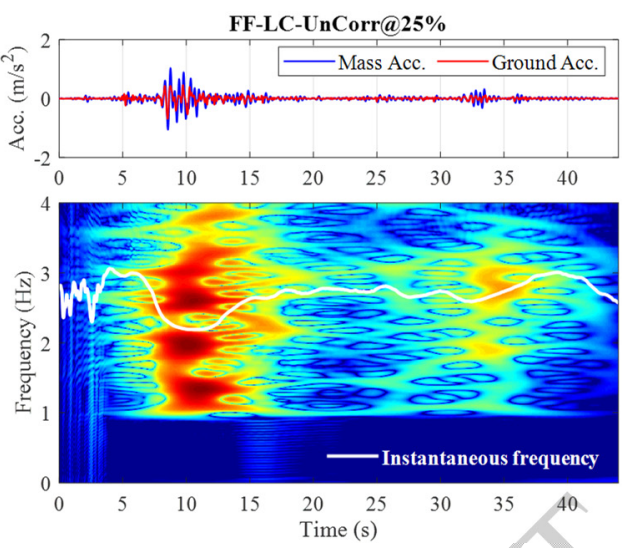

(d)
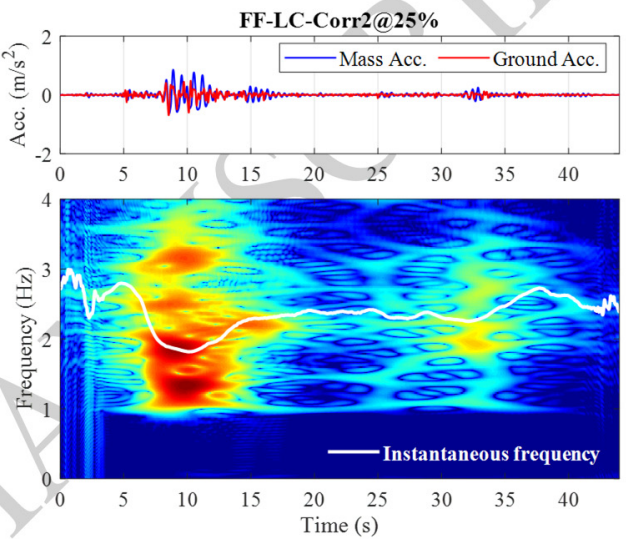

(f)

Fig. 11. Frequency responses of all specimens at slight (25\%) damage level tests obtained by smoothed pseudo Wigner-Ville distribution.

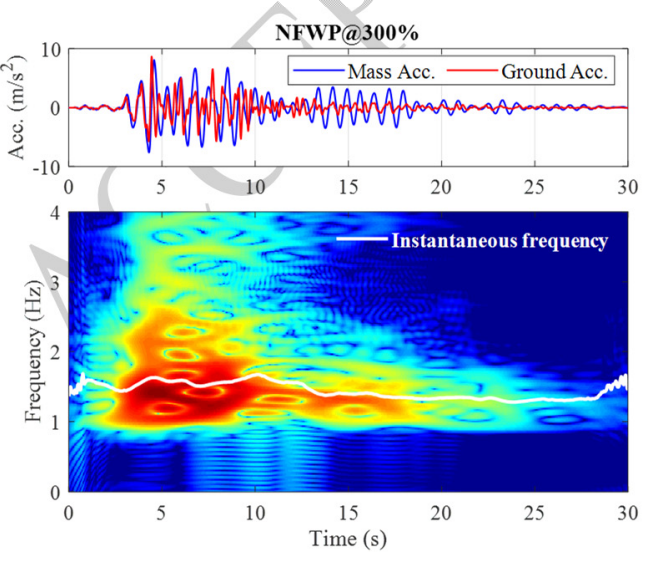

(a)
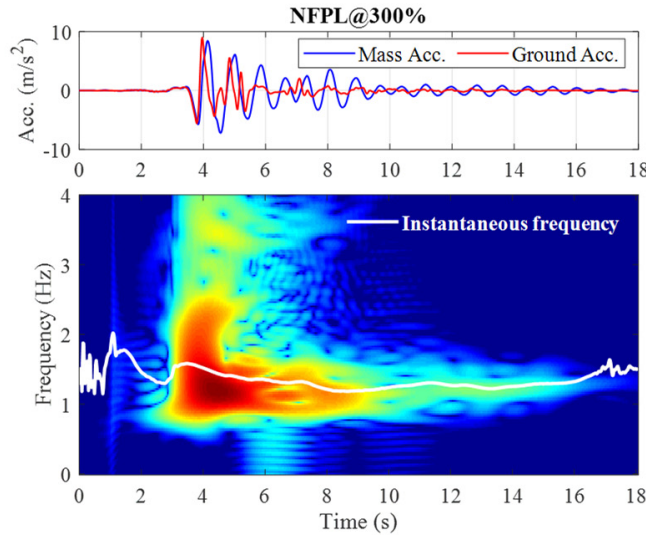

(b) 

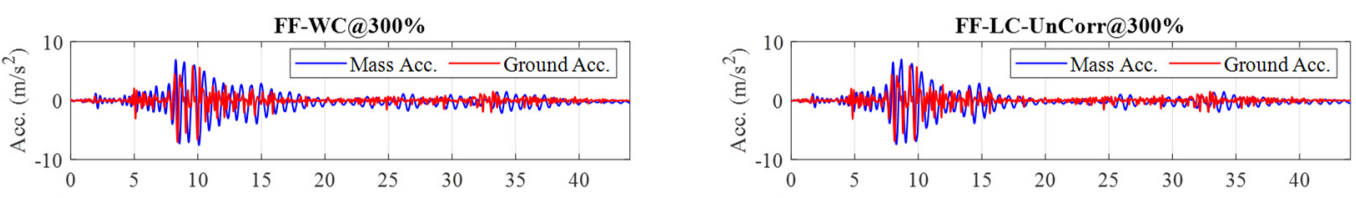

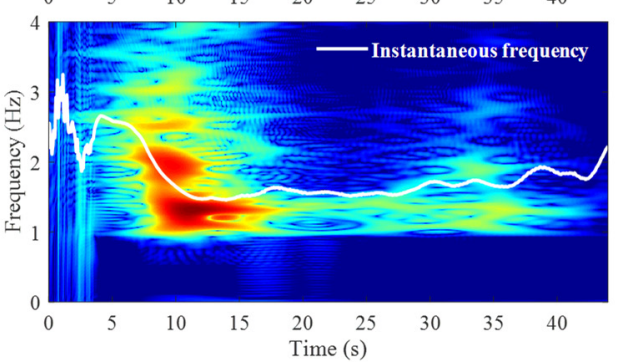

(c)

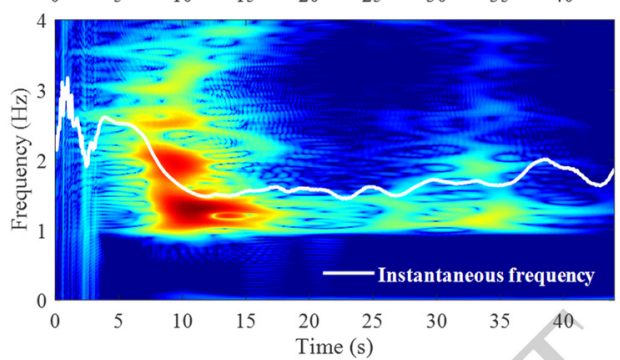

(d)
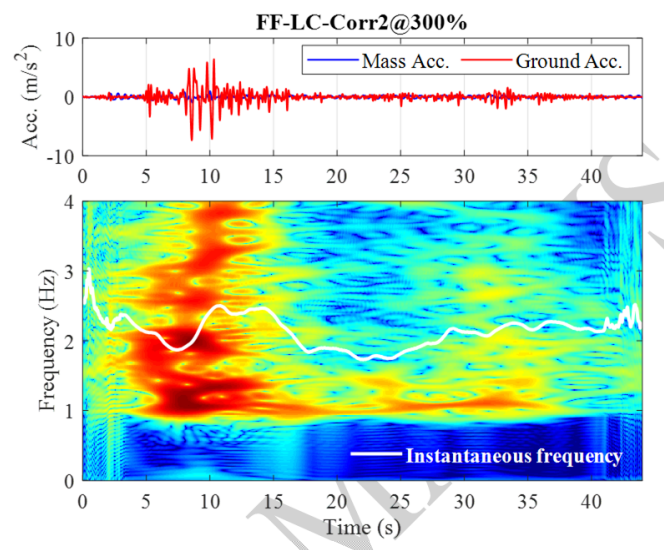

(e)

Figure 12. Frequency responses of all specimens at extensive (300\%) damage level tests obtained by smoothed pseudo Wigner-Ville distribution.

\section{A comparison of the MLR, HT and WVD algorithms}

The real-time frequency estimates of slight (25\%) and extensive (300\%) damage level tests obtained by the three proposed algorithms (MLR based on acceleration and displacement, smoothed Hilbert transform (HT), and smoothed pseudo-Wigner-Ville (WVD) based on only acceleration) are compared in Figures 13 and 14. The initial and final frequencies obtained by transfer function estimate (TFE) very low amplitude white noise test are plotted as a reference. These three real-time frequency estimate methods show good agreement with each other in extensive (300\%) damage level tests (Figure 14). It suggests that with the ascend of signal amplitude, the accuracy of time-frequency increases. This is due to the effect of that systematic error is not significant when the structural response is large enough. The frequency estimate of 
two corroded specimens in the $25 \%$ tests [Figures. 13(e) and 13(f)] also shows good agreement. Because, with corrosion-induced material degradation, even low-amplitude excitation can result in severe structural damage.

Results from the uncorroded tests in the $25 \%$ tests [Figures. 13(a)-(d)] indicate that the performance of the acceleration only measurement approaches (the HT and the WVD) are less good at lower response amplitude levels. The frequency response obtained by the MLR is higher than that obtained by the HT and the WVD. The TFE indicates similar results with the MLR. Given the responses of uncorroded columns are almost linear in the $25 \%$ tests, the MLR is believed to provide more credible estimates, despite the noise. The frequency estimate of FFLC-Corr 2 specimen in the $300 \%$ test also shows less good agreement. The rocking movement of this specimen was observed during the experiment (Ge et al., 2019), as the vertical bars were fractured. Therefore, the acceleration response is very small even though the excitation amplitude is large (see Figure 14(e)). On the other hand, the accuracy of the frequency response obtained by the MLR for this rocking column is in doubt. Because it exhibits non-standard hysteresis (see Figure 4), the least-square fit cannot accurately reflect the instantaneous stiffness/frequency.

For the NFWP and NFPL specimens in the $300 \%$ tests, prior to the large-amplitude ground motion, the frequency estimates of the HT and the WVD show different result from the MLR (with force and displacement responses). However, the initial frequency obtained by TFE shows good agreement with the frequency estimated by the MLR. The quick drop of the frequency is believed to be partially caused by concrete crack reopen (Ge et al., 2019). However, without displacement response, it is difficult to capture this phenomenon. This problem is not found in the specimens excited by the $300 \%$ FF ground motion (Figs. 14(c-e)). Therefore, the performance of the HT and the WVD is suspected to be affected by the characteristics of ground motions.

The WVD and MLR produce very similar frequency estimates. This suggests that the WVD (based on acceleration measurements alone) can be used to give a good indication of damage. The Hilbert transform approach produces credible estimates (on average) also. However, the threshold introduced for smoothing the instantaneous frequency obtained by the HT may require calibration. Choosing the threshold needs a trade-off of smoothing efficiency 
and adequacy of signal information. The remaining spikes make the HT difficult to identify localised (in time) abrupt changes in frequency caused by large crack openings with this approach. The TFE can generally estimate the final frequency before/after the test but not during. Additionally, it is not an in-situ field method.

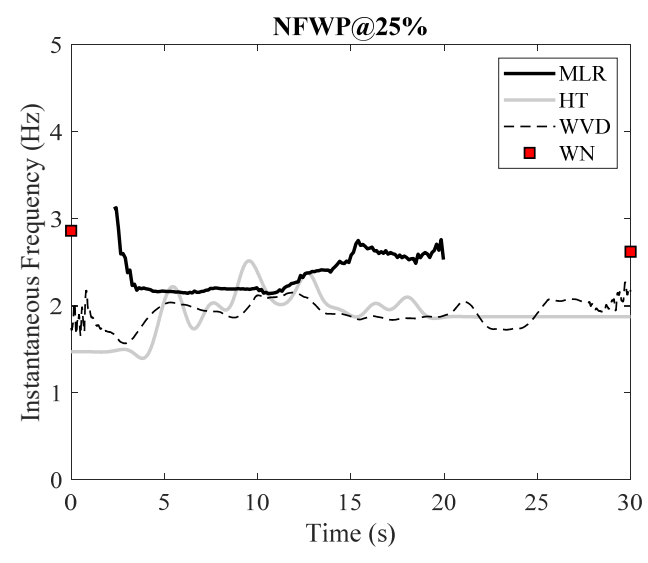

(a)

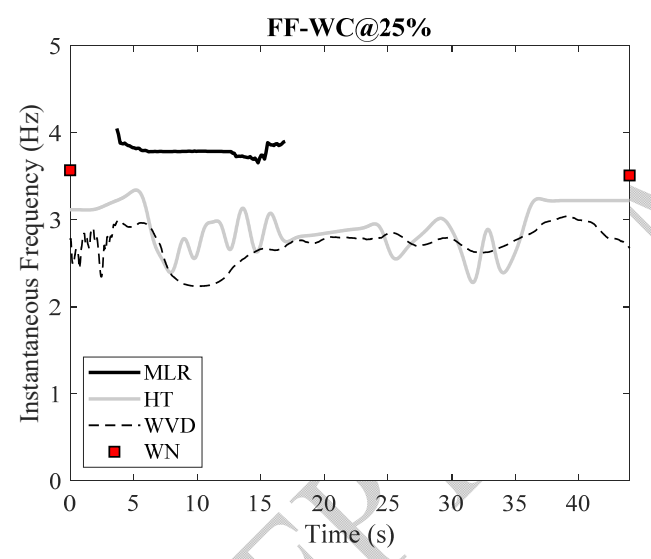

(c)

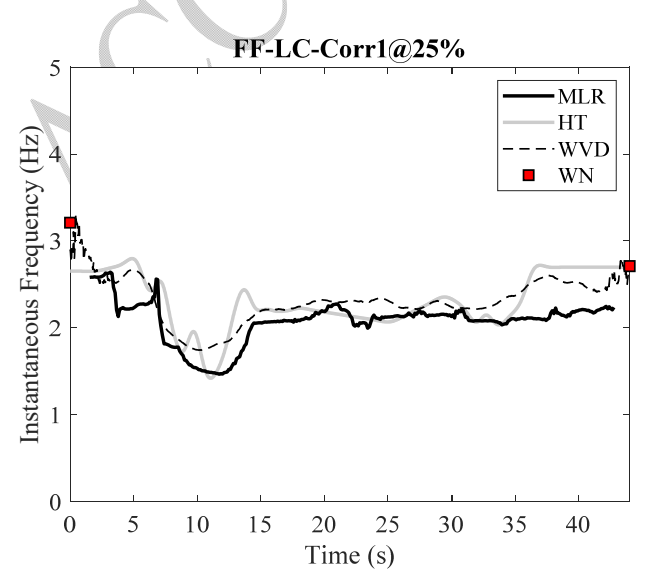

(e)

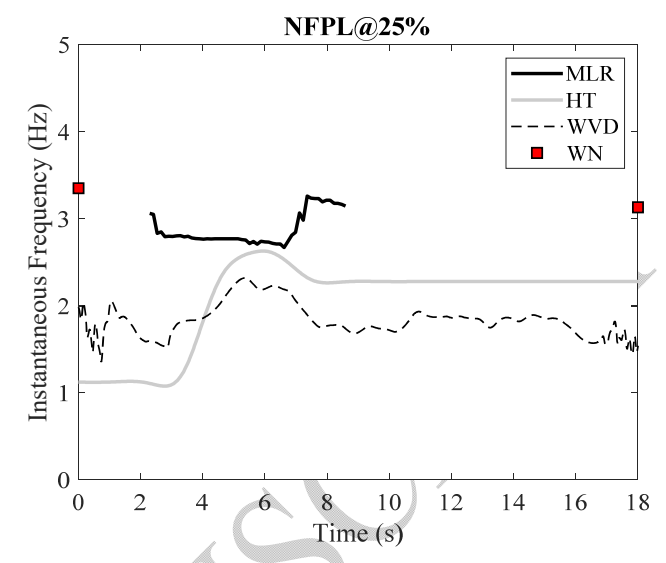

(b)

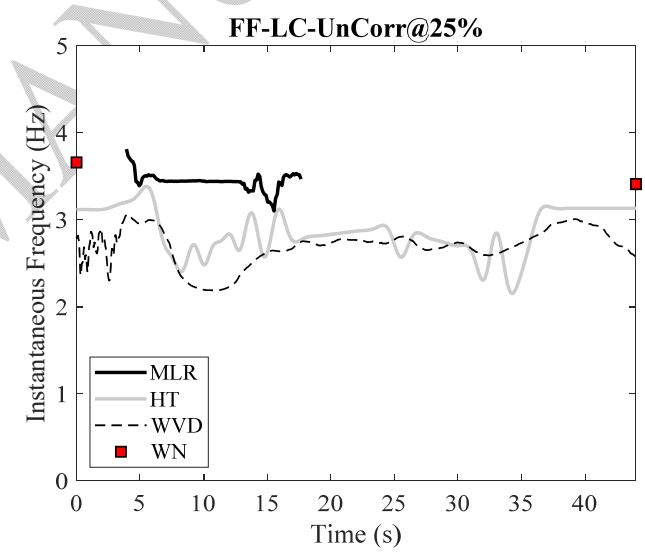

(d)

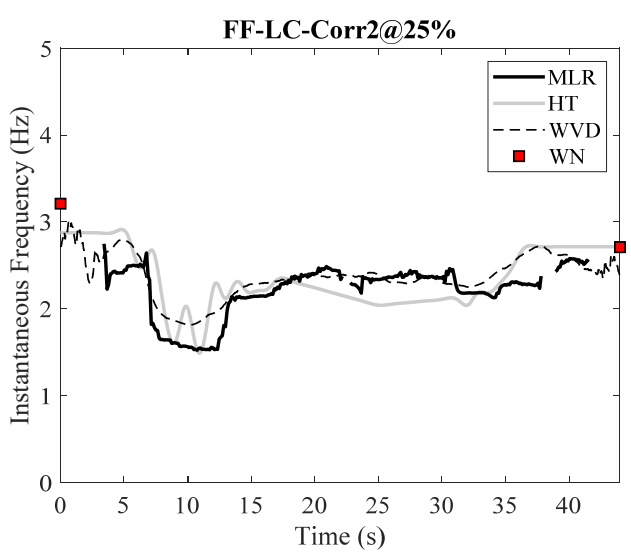

(f)

Figure 13. The comparison of the frequencies of all specimens at slight (25\%) damage level tests 
obtained by the moving linear regression (MLR), the Wigner-Ville distribution (WVD), the Hilbert transform (HT) and the transfer function estimate (TFE).

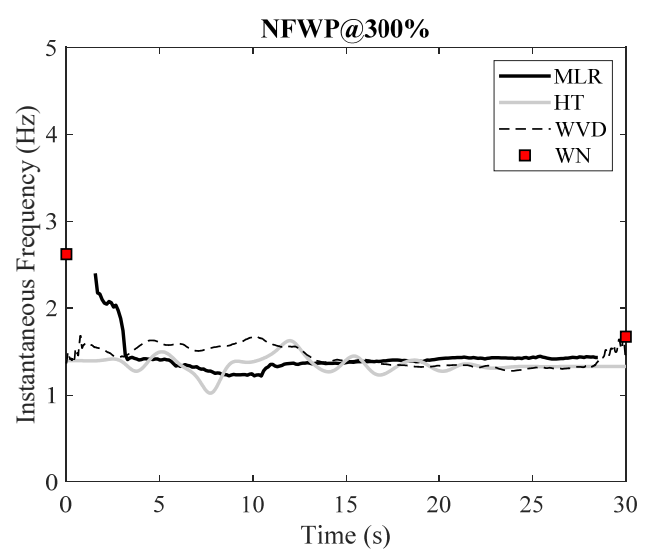

(a)

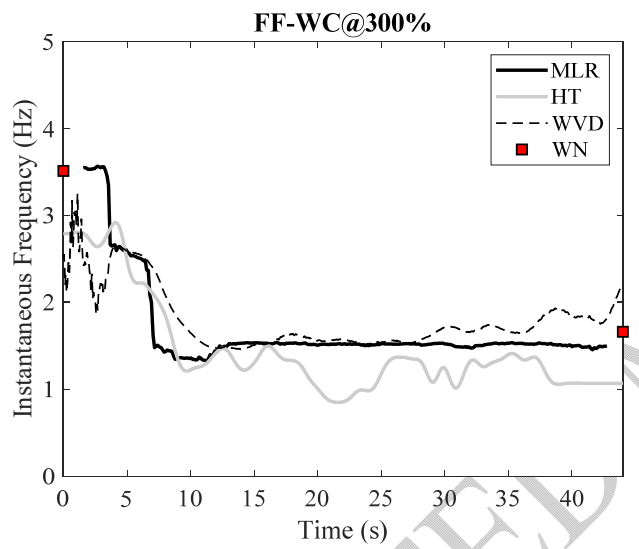

(c)

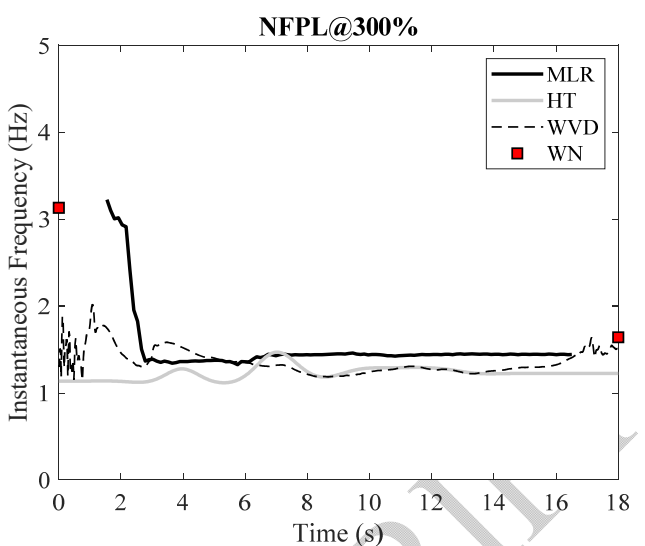

(b)

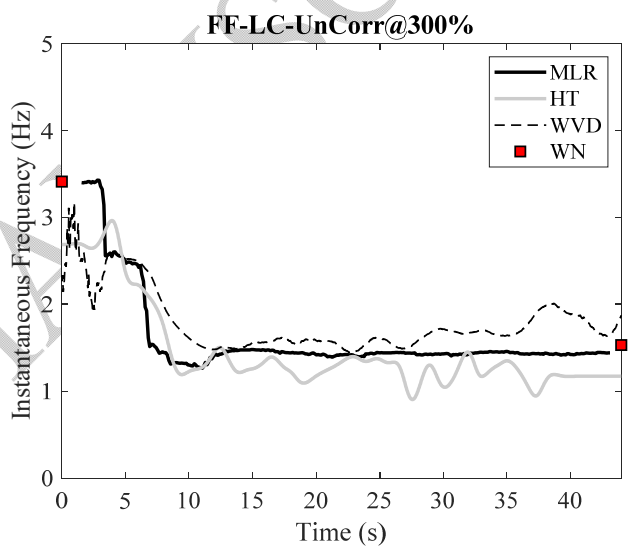

(d)

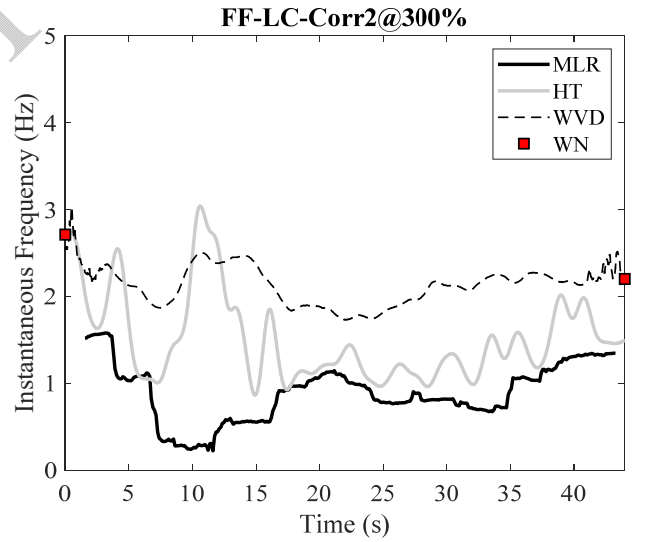

(e)

Figure 14. The comparison of frequencies of all specimens in extensive (300\%) damage level tests obtained by the Moving linear regression (MLR), the Wigner-Ville distribution (WVD), the Hilbert transform (HT) and the white noise transfer function estimate (TFE). 


\section{Conclusions}

This paper investigated the performance of rapid structural damage assessment of RC bridge piers using smoothed Hilbert transform and smoothed pseudo-Wigner-Ville distribution algorithms (using acceleration responses). Six RC columns are experimentally tested using the shaking table tests with various input ground motion characteristics, structural detailing and corrosion levels for a case study. The accuracy of the proposed methods is evaluated in lowand large-amplitude responses respectively. The instantaneous frequency/stiffness of RC columns obtained by time-frequency representative is benchmarked against the MLR (that makes use of force/displacement time series). The following conclusions can be drawn.

- The case study shows that the signal processing of only acceleration data of RC bridge piers measured during earthquakes can be used as rapid damage assessment. The proposed method (the WVD and the HT) can estimate the damage based on instantaneous stiffness/frequency response without extensive instrumentation and data processing required in conventional structural health monitoring approaches.

- For low amplitude tests, on uncorroded piers, the performance of the HT (using acceleration output only) and the WVD (using input/output accelerations) produce similar time-frequency curves but these appear to underestimate system frequency compared with the white-noise (TFE) tests. While the MLR (using response acceleration/displacement) tends to produce more similar frequency estimates to the white noise tests.

- $\quad$ For low amplitude tests, on corroded piers, all three methods HT, WVD and MLR produce very similar time-frequency estimates which are also consistent with the white-noise (TFE) tests.

- For high amplitude tests, on uncorroded piers, All three methods HT, WVD and MLR produce similar time-frequency estimates which are also consistent with the white-noise (TFE) tests. The MLR in particular highlights step like drops in frequencies associated with cover spalling.

- For the high amplitude test, on the corroded pier, all three methods HT, WVD and MLR do not produce similar time-frequency estimates. The reason for this is due to the highly damaged nature of this column that exhibits a rocking/flexural nonlinear response.

- In a rapid assessment scenario, the WVD gives the engineer for more information than the 
HT as it is a multi-valued time-frequency function. The use of predominant frequency (centroidal) from the WVD enables an assessment of changes in system characteristics and hence damage.

- Results indicated that a rapid assessment of undamaged/uncorroded piers for low amplitude events using either HT or WVD may not be robust. However, for the high amplitude event and/or severely corroded columns both HT and WVD can be very useful in identifying additional damage to piers during the earthquake.

In future, the application of the proposed damage assessment method can be benchmarked by other types of structures (e.g. steel, timber or masonry structures) to evaluate its usability. Currently, the trade-off between time and frequency resolutions cannot be avoid in timefrequency analysis. In future, an algorithm with high resolutions in both time and frequency domains is needed. With this algorithm, the rapid damage assessment can be more accurate.

\section{Reference}

Adeli, H., \& Jiang, X. (2006). Dynamic Fuzzy Wavelet Neural Network Model for Structural System Identification. Journal of Structural Engineering, 132(1), 102-111. https://doi.org/10.1061/(ASCE)0733-9445(2006)132:1(102)

Ahlborn, T. M., Shuchman, R., Sutter, L. L., Brooks, C. N., Harris, D. K., Burns, J. W., Endsley, K. A., Evans, D. C., Vaghefi, K., \& Oats, R. C. (2010). The State-of-the-Practice of Modern Structural Health Monitoring for Bridges: A Comprehensive Review.

Alexander, N. A., Chanerley, A. A., Crewe, A. J., \& Bhattacharya, S. (2014). Obtaining Spectrum Matching Time Series Using a Reweighted Volterra Series Algorithm (RVSA). Bulletin of the Seismological Society of America, 104(4), 1663-1673. https://doi.org/10.1785/0120130198

Alipour, A., Shafei, B., \& Shinozuka, M. (2011). Performance evaluation of deteriorating highway bridges located in high seismic areas. Journal of Bridge Engineering, 16(5), 597-611. https://doi.org/10.1061/(ASCE)BE.1943-5592.0000197

Ancheta T. D., Darragh, R. B., Stewart, J. P., Seyhan, E., Silva, W. J., Chiou, B. S. J., Wooddell, K. E., Graves, R. W., Kottke, A. R., Boore, D. M., Kishida, T., \& Donahue, J. L. (2013). PEER NGAWest2 Database.

Auger, F., Flandrin, P., Gonçalvès, P., \& Lemoine, O. (1996). Time-frequency toolbox - for use with 
MATLAB.

Berinde, F. C., Gillich, G. R., \& Chioncel, C. P. (2006). Structure monitoring and evaluation using vibroacoustic method supported by the Wigner-Ville Distribution. Romanian Journal of Acoustics and Vibration, 7, 61-65.

Bradford, S. C., Yang, J., \& Heaton, T. H. (2006). Variations in the dynamic properties of structures: the Wigner-Ville distribution. The 8th U.S. National Conference on Earthquake Engineering, No. 1439. Caltrans. (2013). Seismic Design Criteria, Version 1.7.

CEN.EN. (2010). Eurocode 8 - Design provisions for earthquake resistance of structures - Part 2: Bridges.

Chang, G. A., \& Mander, J. B. (1994). Seismic energy based fatigue damage analysis of bridge columns: part I - evaluation of seismic capacity.

Chen, G., Chen, J., \& Dong, G. (2013). Chirplet Wigner-Ville distribution for time-frequency representation and its application. Mechanical Systems and Signal Processing, 41(1-2), 1-13. https://doi.org/10.1016/j.ymssp.2013.08.010

Chen, Y., \& Feng, M. Q. (2003). A technique to improve the empirical mode decomposition in the Hilbert-Huang transform. Earthquake Engineering and Engineering Vibration, 2(1), 75-85. https://doi.org/10.1007/BF02857540

Choe, D. E., Gardoni, P., Rosowsky, D., \& Haukaas, T. (2008). Probabilistic capacity models and seismic fragility estimates for RC columns subject to corrosion. Reliability Engineering \& System Safety, 93(3), 383-393. https://doi.org/10.1016/J.RESS.2006.12.015

Claasen, T. A. C. M., \& Mecklenbräuker, W. F. G. (1980). The Wigner distribution-a tool for timefrequency signal analysis Part I: continuous-time signals. Philips Journal of Research, 35(3), 217250.

Cruz, P. J. S., \& Salgado, R. (2009). Performance of vibration-based damage detection methods in bridges. Computer-Aided Civil and Infrastructure Engineering, 24(1), 62-79. https://doi.org/10.1111/j.1467-8667.2008.00546.x

Cusson, D., \& Paultre, P. (1994). High-Strength Concrete Columns Confined by Rectangular Ties. Journal of Structural Engineering, 120(3), 783-804. https://doi.org/10.1061/(ASCE)07339445(1994)120:3(783)

Dätig, M., \& Schlurmann, T. (2004). Performance and limitations of the Hilbert-Huang transformation 
(HHT) with an application to irregular water waves. Ocean Engineering, 31(14-15), 1783-1834. https://doi.org/10.1016/j.oceaneng.2004.03.007

Dhakal, R. P., \& Maekawa, K. (2002). Reinforcement Stability and Fracture of Cover Concrete in Reinforced Concrete Members. Journal of Structural Engineering, 128(10), 1253-1262. https://doi.org/10.1061/(ASCE)0733-9445(2002)128:10(1253)

Dizaj, E. A., Madandoust, R., \& Kashani, M. M. (2018). Probabilistic seismic vulnerability analysis of corroded reinforced concrete frames including spatial variability of pitting corrosion. Soil Dynamics and Earthquake Engineering, 114, 97-112.

Dizaj, E. A., Madandoust, R., \& Kashani, M. M. (2019). Exploring the impact of chloride-induced corrosion on seismic damage limit states and residual capacity of reinforced concrete structures. Structure and Infrastructure Engineering, 14(6), 714-729.

El-Bahy, A., Kunnath, S. K., Stone, W. C., \& Taylor, A. W. (1999). Cumulative seismic damage of circular bridge columns: benchmark and low-cycle fatigue tests. ACI Structural Journal, 96(4), 633-641.

El Shafie, A., Noureldin, A., McGaughey, D., \& Hussain, A. (2012). Fast orthogonal search (FOS) versus fast Fourier transform (FFT) as spectral model estimations techniques applied for structural health monitoring (SHM). Structural and Multidisciplinary Optimization, 45(4), 503-513. https://doi.org/10.1007/s00158-011-0695-y

Feldman, M. (2014). Hilbert transform methods for nonparametric identification of nonlinear time varying vibration systems. Mechanical Systems and Signal Processing, 47(1-2), 66-77. https://doi.org/10.1016/J.YMSSP.2012.09.003

FEMA-P695. (2009). Quantification of building seismic performance factors.

Foster, S. J. (2001). On Behavior of High-Strength Concrete Columns: Cover Spalling, Steel Fibers, and Ductility. ACI Structural Journal, 98(4), 583-589. https://doi.org/10.14359/10301

Gaal, G. C. M. (2004). Prediction of Deterioration of Concrete Bridges. Delft University Press.

Ge, X., Dietz, M. S., Alexander, N. A., \& Kashani, M. M. (2019). Nonlinear dynamic behaviour of severely corroded reinforced concrete columns: shaking table study. Bulletin of Earthquake Engineering, 17, 1-27.

Ghosh, J., \& Padgett, J. E. (2010). Aging considerations in the development of time-dependent seismic fragility curves. Journal of Structural Engineering, 136(12), 1497-1511. 
https://doi.org/10.1061/(ASCE)ST.1943-541X.0000260

Giurgiutiu, V., \& Yu, L. (2003). Comparison of Short-time Fourier Transform and Wavelet Transform of Transient and Tone Burst Wave Propagation Signals For Structural Health Monitoring. 4th International Workshop on Structural Health Monitoring.

Guo, Y. L., \& Kareem, A. (2016a). Non-stationary frequency domain system identification using timefrequency representations. Mechanical Systems and Signal Processing, 72-73, 712-726.

Guo, Y. L., \& Kareem, A. (2016b). System identification through nonstationary data using TimeFrequency Blind Source Separation. Journal of Sound and Vibration, 371, 110-131.

Huang, N. E., Shen, Z., Long, S. R., Wu, M. C., Shih, H. H., Zheng, Q., Yen, N.-C., Tung, C. C., \& Liu, H. H. (1998). The empirical mode decomposition and the Hilbert spectrum for nonlinear and nonstationary time series analysis. Proceedings of the Royal Society of London. Series A: Mathematical, Physical and Engineering Sciences, 454(1971), 903-995. https://doi.org/10.1098/rspa.1998.0193

Iatsenko, D., McClintock, P. V. E., \& Stefanovska, A. (2016). Extraction of instantaneous frequencies from ridges in time-frequency representations of signals. Signal Processing, 125, 290-303.

Kashani, M. M., Crewe, A. J., \& Alexander, N. A. (2017). Structural capacity assessment of corroded RC bridge piers. Proceedings of the Institution of Civil Engineers - Bridge Engineering, 170(1), 2841. https://doi.org/10.1680/jbren.15.00023

Kashani, M. M., Ge, X., Dietz, M. S., Crewe, A. J., \& Alexander, N. A. (2019). Significance of non-stationary characteristics of ground-motion on structural damage: shaking table study. Bulletin of Earthquake Engineering, 17, 1-23.

Kashani, M. M., Maddocks, J., \& Dizaj, E. A. (2019). Residual Capacity of Corroded Reinforced Concrete Bridge Components: State-of-the-Art Review. Journal of Bridge Engineering, 24(7), 03119001.

Kashaní, M. M., Málaga-Chuquitaype, C., Yang, S., \& Alexander, N. A. (2017). Influence of nonstationary content of ground-motions on nonlinear dynamic response of RC bridge piers. Bulletin of Earthquake Engineering, 15(9), 3897-3918. https://doi.org/10.1007/s10518-017-0116-8

Kashani, M. M., Salami, M. R., Goda, K., \& Alexander, N. A. (2018). Non-linear flexural behaviour of $\mathrm{RC}$ columns including bar buckling and fatigue degradation. Magazine of Concrete Research, 70(5), 231-247. https://doi.org/10.1680/jmacr.16.00495

Khoa, N. V. (2013). Monitoring a sudden crack of beam-like bridge during earthquake excitation. 
Vietnam Journal of Mechanics, 35(3), 189-202. https://doi.org/10.15625/0866-7136/35/3/2561

Kijewski-Correa, T. (2005). GPS: a new tool for structural displacement measurements. APT Bulletin, $36(1), 13-18$.

Kim, T. H., Lee, K. M., Chung, Y. S., \& Shin, H. M. (2005). Seismic damage assessment of reinforced concrete bridge columns. Engineering Structures, 27(4), 576-592. https://doi.org/10.1016/J.ENGSTRUCT.2004.11.016

Kunwar, A., Jha, R., Whelan, M., \& Janoyan, K. (2013). Damage detection in an experimental bridge model using Hilbert-Huang transform of transient vibrations. Structural Control and Health Monitoring, 20(1), 1-15. https://doi.org/10.1002/stc.466

Lehman, D., Moehle, J., Mahin, S., Calderone, A., \& Henry, L. (2004). Experimental Evaluation of the Seismic Performance of Reinforced Concrete Bridge Columns. Journal of Structural Engineering, 130(6), 869-879. https://doi.org/10.1061/(ASCE)0733-9445(2004)130:6(869)

Li, Z., Park, H. S., \& Adeli, H. (2017). New method for modal identification of super high-rise building structures using discretized synchrosqueezed wavelet and Hilbert transforms. The Structural Design of Tall and Special Buildings, 26(3), e1312.https://doi.org/10.1002/tal.1312

Loutridis, S. J. (2004). Damage detection in gear systems using empirical mode decomposition. Engineering Structures, 26(12), 1833-1841.

Martin, W., \& Flandrin, P. (1985). Detection of changes of signal structure by using the Wigner-Ville spectrum. Signal Processing, 8(2), 215-233.

Matheney, M. P., \& Nowack, R. L. (1995). Seismic attenuation values obtained from instantaneousfrequency matching and spectral ratios. Geophysical Journal International, 123(1), 1-15. https://doi.org/10.1111/j.1365-246X.1995.tb06658.x

Melhem, H., \& Kim, H. S. (2003). Damage detection in concrete by Fourier and wavelet analyses. Journal of Engineering Mechanics, 129(5), 571-577. https://doi.org/10.1061/(ASCE)07339399(2003)129:5(571)

Nagarajaiah, S., \& Basu, B. (2009). Output only modal identification and structural damage detection using time frequency and wavelet techniques. Earthquake Engineering and Engineering Vibration, $8(4), 583-605$.

Pines, D., \& Salvino, L. (2006). Structural health monitoring using empirical mode decomposition and the Hilbert phase. Journal of Sound and Vibration, 294(1-2), 97-124. 
Qiao, L., Esmaeily, A., \& Melhem, H. G. (2012). Signal pattern recognition for damage diagnosis in structures. Computer-Aided Civil and Infrastructure Engineering, 27(9), 699-710. https://doi.org/10.1111/j.1467-8667.2012.00766.x

Roy, T. B., Banerji, S., Panigrahi, S. K., Chourasia, A., Tirca, L., \& Bagchi, A. (2019). A novel method for vibration-based damage detection in structures using marginal Hilbert spectrum. In A. Rao \& K. Ramanjaneyulu (Eds.), Recent Advances in Structural Engineering (pp. 1161-1172). Springer. https://doi.org/10.1007/978-981-13-0362-3_92

Salvino, L. W., Pines, D. J., Todd, M. D., \& Nichols, J. (2003). Signal processing and damage detection in a frame structure excited by chaotic input force. In R. C. Smith (Ed.), SPIE 5049, Smart Structures and Materials 2003: Modeling, Signal Processing, and Control (Vol. 5049, p. 639). International Society for Optics and Photonics. https://doi.org/10.1117/12.484012

Sheikh, S. A., \& Khoury, S. S. (1993). Confined concrete columns with stubs. ACI Structural Journal, 90(4), 414-431.

Shin, M., \& Andrawes, B. (2011). Emergency repair of severely damaged reinforced concrete columns using active confinement with shape memory alloys. Smart Materials and Structures, 20(6), 065018. https://doi.org/10.1088/0964-1726/20/6/065018

Si, L., Wang, Q., Si, L., \& Wang, Q. (2016). Rapid multi-damage identification for health monitoring of laminated composites using piezoelectric wafer sensor arrays. Sensors, 16(5), 638. https://doi.org/10.3390/s16050638

Spanos, P. D., \& Failla, G. (2005). Wavelets: Theoretical concepts and vibrations related applications. The Shock and Vibration Digest, 37(5), 359-376.

Spanos, P. D., Giaralis, A., Politis, N. P., \& Roesset, J. M. (2007). Numerical treatment of seismic accelerograms and of inelastic seismic structural responses using harmonic Wavelets. ComputerAided Civil and Infrastructure Engineering, 22(4), 254-264.

Staszewski, W. J., \& Robertson, A. N. (2007). Time-frequency and time-scale analyses for structural health monitoring. Philosophical Transactions of the Royal Society A, 365, 449-477. https://doi.org/10.1098/rsta.2006.1936

Tang, B. P., Liu, W. Y., \& Song, T. (2010). Wind turbine fault diagnosis based on Morlet wavelet transformation and Wigner-Ville distribution. Renewable Energy, 35(12), 2862-2866.

The MathWorks Inc. (2019). MATLAB (9.6.0.1011450 (R2019a) Prerelease). The MathWorks Inc. 
Thomson, E., Bendito, A., \& Flórez-López, J. (1998). Simplified Model of Low Cycle Fatigue for RC Frames. Journal of Structural Engineering, 124(9), 1082-1085. https://doi.org/10.1061/(ASCE)0733-9445(1998)124:9(1082)

Tobbi, H., Farghaly, A. S., \& Benmokrane, B. (2014). Behavior of Concentrically Loaded FiberReinforced Polymer Reinforced Concrete Columns with Varying Reinforcement Types and Ratios. ACI Structural Journal, 111(2), 375-386. https://doi.org/10.14359/51686528

Ville, J. (1948). Theorie et applications de la notion de signal analytique. Cables et Transmission, 1, 6174.

Vold, H., Crowley, J., \& Rocklin, G. T. (1984). New ways of estimating frequency response functions. Sound \& Vibration, 18(11), 34-38.

Wigner, E. (1932). On the quantum correction for thermodynamic equilibrium. Physical Review, 40(5), 749-759. https://doi.org/10.1103/PhysRev.40.749

Wong, L. A., \& Chen, J. C. (2001). Nonlinear and chaotic behavior of structural system investigated by wavelet transform techniques. International Journal of Non-Linear Mechanics, 36(2), 221-235. https://doi.org/10.1016/S0020-7462(00)00007-X

Wu, J. D., \& Chiang, P. H. (2009). Application of Wigner-Ville distribution and probability neural network for scooter engine fault diagnosis. Expert Systems with Applications, 36(2), 2187-2199.

Youssef, M. A., \& Ghobarah, A. (1999). Strength deterioration due to bond slip and concrete crushing in modeling of reinforced concrete members. ACI Structural Journal, 96(6), 956-966. https://doi.org/10,14359/770 